\title{
A RETROSPECTIVE AND PROSPECTIVE LOOK AT THE ROLE OF GENETICS IN MATING
}

\author{
SYSTEMS: TOWARD A BALANCED VIEW OF THE SEXES
}

\author{
DAVID F. WESTNEAT \\ Center for Ecology, Evolution, and Behavior \\ T. H. Morgan School of Biological Sciences \\ 101 Morgan Building \\ University of Kentucky \\ Lexington, KY 40506-0225
}

\begin{abstract}
Genetic tools have recently altered our views of mating patterns in many taxa. The results have expanded the range of hypotheses being tested in several major subject areas; including the types of selective forces acting on female reproductive behavior, the relationship between paternity and paternal care, the operation of sexual selection, and the ecology of mating. Despite the progress genetics have made in these areas, many fundamental questions remain unanswered. Moreover, genetic tools have revealed considerable unexplained diversity in mating patterns within many taxa. Current conceptual approaches provide only partial explanations for such diversity, and tend to emphasize one sex over the other. I review some new advances in selection theory and quantitative genetic models which, when integrated with previous paradigms, offer some new insights on mating. Although the use of molecular genetic tools to study mating will continue, these other genetic approaches could also become important for progress toward understanding the evolution of male and female interactions over reproduction.
\end{abstract}

\section{Introduction}

Human reason has this peculiar fate that in one species of its knowledge it is burdened by questions which, as prescribed by the very nature of reason itself, it is not able to ignore, but which, as transcending all its powers, it is also not able to answer. -- Immanuel Kant, Critique of Pure Reason (1781). 
The study of animal mating behavior has steadily grown over the past 20 years, both in numbers of studies and their complexity. This growth is due to a combination of factors, one of which is the empirical advances brought about by new genetic tools. Many new questions have been stimulated by the results coming from these genetic studies, and the study of mating patterns, in my opinion, has never been more exciting. However, the results coming from the use of genetic tools have spawned new challenges as well. A general conclusion emerging from these studies is that a stunning range of mating patterns exists within almost any taxon of animals. The causes of such diversity are complex, and seeking a full understanding might just qualify as matching Kant's criteria of an area with compelling yet unanswerable questions. In an attempt to be more optimistic than Kant, I will suggest in this chapter that if questions about diversity are to be satisfactorily answered, then a start will be to develop a more comprehensive framework for understanding diversity in complex phenotypic traits, especially those involved in dynamic interactions with other individuals. Many of the components of a suitable conceptual approach are already available, but are perhaps not yet fully integrated. Some evolutionary approaches recently developed by quantitative geneticists may help provide a more synthetic conceptual framework. And so, my aim in this chapter is to document the role of genetic tools in uncovering this troublesome diversity, and then to look forward to the ways in which genetics might answer the new questions this diversity leads us to ask.

\section{Uncovering mating patterns}

\subsection{Setting the stage: Evolving views on mating}

Diversity in mating is not a new insight. Some of the earliest recorded scientific observations of animals include descriptions of variation in mating behavior among species. For example, Aristotle noted that among birds, "Some, again, are peculiarly salacious, as the partridge, the barn-door cock and their congeners; others are inclined to chastity, as the whole tribe of crows, for birds of this kind indulge but rarely in sexual intercourse (Aristotle $350 \mathrm{BC}$ )."

Darwin (1871) also noted conspicuous differences among species. Morphological features and behavioral displays involved in mating were not only different between the sexes, but the extent of those differences varied among species. Darwin realized that the way he had presented natural selection (as a struggle for survival) would not explain many aspects of sexual dimorphism. He proposed that there was also variance in access to mates between individuals of the same sex, thereby producing sexual selection on traits involved in the struggle for mates. Variation in the strength and direction of this selective force might then provide an explanation for variation in sexual traits.

The full implications of Darwin's ideas in terms of the selective forces acting on the sexes were not appreciated for some time. Many researchers instead focused on the obvious joint interests of males and females in reproduction and arguments about how such traits influenced populations or the species. Welty (1972) for example, describes the displays leading to pairing in birds as adaptations to avoid hybridization. Another often mentioned function of courtship is to coordinate the events leading to ovulation (e.g., Stresemann 1927-34). In addition, some researchers viewed mating interactions as a series of behaviors cobbled together from other activities. Andrew (1961a, b) for example proposed that courtship was composed of behavioral elements of aggression, fear, wariness, nest-building, parental care, and juvenile begging that eventually gave way to the formation of a pair bond. 
The joint interests of males and females clearly are important and have perhaps been downplayed too much recently. However, it is clear that the common interest that males and females have in producing a zygote fails to provide an adequate explanation for widespread diversity in mating behavior. How can a common selective force explain the presence of sophisticated coordination of courtship in many birds and the lack of such displays in other birds and many mammals? By the mid1960s, questions about mating patterns had shifted from cooperation between socially monogamous mates to male-female interactions in socially polygynous species, in which the sexes behaved in dramatically different ways. Verner (1964), Willson (1966) and Orians (1969) focused on the idea that ecological factors influenced the distributions of females in space and time, thereby affecting male defense of females. These ideas signified a change in thinking from the joint interests of the sexes to differences between the sexes in fitness components. Male success seemed limited only by the number of mates; female success more by how many young she could rear.

The idea that the sexes might be under different selection pressures became much clearer when Parker et al. (1972) modeled the evolution of anisogamy. A fundamental trade-off facing any sexual reproducer is that it can only increase gamete number at the expense of gamete size or vice-versa. The models of Parker et al (1972) revealed that the existence of variation in gamete size among individuals in a population could often lead to disruptive selection on gamete size. Male (small gamete producer) and female (large gamete producer) thus are two alternative reproductive strategies, differing in gamete size and number, that exist within a single population.

In 1972, Trivers took this insight about anisogamy and produced a series of far-reaching predictions about male and female reproductive behavior. Trivers predicted that because male success is limited more by the number of mates fertilized than the number of gametes produced, selection should have shaped males to attempt matings in a variety of ways. Thus Trivers predicted that males would gain offspring through a mixture of behavioral tactics. In birds, for example, he suggested that males might pair with one female but then seek additional matings, perhaps even with the social mates of other males. If so, then his paternity in offspring might always be at some risk, which would select, in turn, for males to behave in ways that reduce that risk.

Some tests of Trivers ideas existed already in 1972; others appeared shortly thereafter. In insects, alternative reproductive tactics began being widely documented through detailed observation. Parker (1970), for example, studied the mating tactics of male dungflies. Competition to fertilize the eggs of females was intense, and affected by the conflicting demand that more time spent copulating with a single female meant more eggs were fertilized, but at a cost of fewer mates encountered. Because the exact costs and benefits depended on what other males did, Parker incorporated game theory into his analysis of the most adaptive behavior pattern. Similarly, Thornhill $(1976,1980)$ found that male scorpionflies attempted to copulate with females in a diversity of ways that depended on food supply and female preference for nuptial gifts. These two studies began to emphasize that mating behaviors were games within and between sexes; that is, what one individual did might affect the fitness consequences of the behaviors exhibited by the other. Not only was this relevant generally, but the consequences were of particular importance to understanding mating behavior.

Trivers' (1972) predictions, and the evidence of competition for fertilizations in insects, raised questions about mating behavior in other taxa. However, in fish, mammals, and especially birds, behavioral observations only provided slight hints. Males behaved as if paternity were at risk by guarding their mates (e.g., Beecher \& Beecher 1979, Hoogland \& Sherman 1976). Furthermore, 
detailed studies in ducks and seabirds were revealing numerous instances of males attempting to copulate with the mates of other males (extra-pair copulations, EPCs), sometimes quite forcibly (e.g., Barash 1977, Birkhead 1978, McKinney et al. 1983). Similar evidence of multiple matings by females appeared in other taxa (e.g., Smith 1984). These behaviors suggested that patterns of paternity might be different from the observed social associations. If Trivers' (1972) ideas were to be fully tested, researchers needed to know the paternity of offspring (e.g., Sherman 1981). Conceptual interest in paternity was growing (e.g., Smith 1984) and empirical evidence from behavioral observations was providing tantalizing but incomplete tests of new hypotheses. Better methods of assessing mating patterns were needed, and hence the motivation for using genetic markers increased.

Human blood-type was one genetic marker that had been used for decades to examine paternity in humans (Neel \& Schull 1954), although publication of general findings on human mating patterns were considerably delayed. Several studies on mammals and birds in the late 1970s and early 1980s using assays of protein polymorphism provided useful information on mating patterns.

McCracken \& Bradbury (1977) published a study of paternity in bats. Other studies in mammals soon followed (e.g., Hanken \& Sherman 1981, Foltz 1981). In birds, the first genetic study made use of plumage markers in a captive population of ducks to reveal that extra-pair fertilizations (EPFs) from forced EPCs were possible (Burns et al. 1980). The first study of free-living birds used asymmetries in tarsus heritabilities (e.g., Alatalo et al. 1984), but was soon followed by studies using protein markers. Gowaty \& Karlin (1984), Gavin \& Bollinger (1985), Joste et al (1985), and Mumme et al. (1985) all found several mismatched young using these techniques, suggesting that EPFs at least sometimes occurred in the wild.

\subsection{Rampant EPFs in indigo buntings}

This was all prehistory to me. I began graduate school in 1982, and, being fairly naive, set out to test the idea that paternity might influence paternal behavior in indigo buntings (Passerina cyanea). Indigo buntings were known to be predominantly socially monogamous (about $85-90 \%$ of breeding units were composed of one male and one female; Carey \& Nolan 1979), and therefore similar to most

birds. They were also similar to many other birds in that copulations were relatively hard to observe. My advisor, Haven Wiley, mentioned that I might want to learn protein electrophoresis in order to do paternity analyses (see Fig. 1 for example). We hoped that we might get lucky and detect a handful of EPFs, perhaps sufficient to have a modest sample size with which to test some ideas about paternity. 


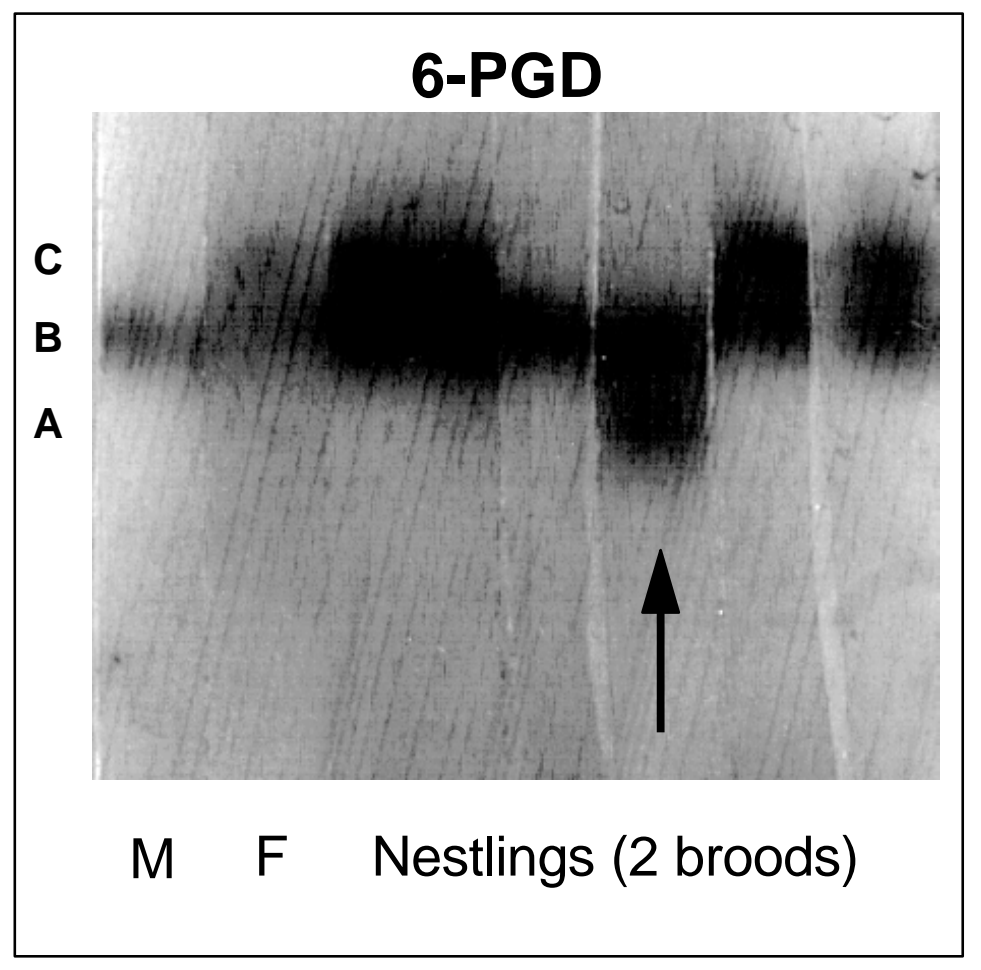

Figure 1. Results of staining tissue samples of a family of indigo buntings (male, female, and two broods of nestlings) for 6-phosphoglucodehydrogenase. One nestling (arrow) has a genotype (AB) that is impossible from the combination of the parents (BB and CB), indicating a likely extra-pair fertilization (Westneat 1987a).

The results were astounding. Instead of a handful of exclusions (e.g., Fig. 1), I found that about $15 \%$ of the nestlings had genotypes incompatible with those of the putative parents (Westneat 1987a). Given that the markers would only detect about $40 \%$ of the cases, this meant that about $35 \%$ of the offspring were descendent from extra-pair males (Westneat et al. 1987). We were stunned at the implications of this result. Underneath the seemingly well understood social mating pattern of this species existed a hidden set of behaviors producing a very different pattern of actual matings. All sorts of fascinating new questions arose about the nature of male-female interactions. The result was so different than expected that I was initially worried that I had not done the protein work correctly.

\subsection{The molecular revolution}

In 1985, Alec Jeffreys and colleagues (Jeffreys et al. 1985) reported the discovery of sections of human DNA containing tandem repeats of modestly long sequences of bases. These tandem repeats were common in the genome and highly polymorphic for the number of repeats within populations. The utility of these regions of DNA for answering questions of identity and kinship was immediately obvious. Within two years, studies using these techniques to study animal mating systems began to be published (e.g., Burke 1987). Since then, an explosion of new results has appeared in many taxa and employing a wide range of different molecular techniques (reviewed in Birkhead \& Møller 1998). Use of these techniques, particularly in studies of mating patterns in birds, is now almost a routine aspect of mating system research. 
The results of all this work have revealed that indigo buntings are not alone among birds in having a 'hidden' mating system. Two-thirds of nearly 100 studied avian species show frequencies of EPFs that exceed 5\%. Many of the North American wood warblers, all predominantly socially monogamous, have around 30\% EPFs (e.g., Stutchbury et al. 1994, Yezerinac et al. 1995, Mays \& Ritchison, unpublished data). Some highly socially monogamous species, such as tree swallows (Tachycineta bicolor) and reed buntings (Emberiza schoenniclus), have frequencies exceeding 50\% (Lifjeld et al. 1993, Dixon et al. 1994). At the highest end of the spectrum, the monogamous cooperatively breeding splendid (Malurus splendins) and superb (M. cyaneus) fairy wrens of Australia have frequencies over 65\% and as high as 80\% (Brooker et al. 1990, Mulder et al. 1994).

Such results have not been confined to birds. Genetic tools have been extremely useful and revealing in other taxa as well. Genetic markers have identified variable mating patterns in mammals (e.g., Pemberton et al. 1992, Hogg \& Forbes 1997; Gomendio et al. 1998) and reptiles (Ollson \& Madsen 1998), and have been applied to insects, fishes, and amphibians (e.g., reviews in Birkhead \& Møller 1998). The overwhelming result of the several hundred genetic studies to date is that females in a wide variety of species routinely have eggs within a breeding episode fertilized by more than one male. Many intriguing new lines of study have been stimulated by these genetic results. Here, I will briefly review some of the questions which I see as the most important. I will focus more on birds than on other taxa, because I know them best, but will reference other taxa as appropriate.

\section{Questions about mating patterns and the future of genetic markers}

\subsection{Female reproductive strategies}

Trivers (1972) was correct in his predictions about male mating behavior; males clearly pursue additional matings in a variety of ways and attempt to protect their paternity with each particular mate. However, Trivers was only half right. His interesting contributions focused on male behavior, and so he missed the possibility that females also might engage in mixed reproductive strategies. An important consequence of recent genetic studies has been the growing evidence that females also sometimes use a mix of tactics within a single breeding episode. An especially exciting aspect of the field today is a shift toward asking more focused questions about variability in female reproductive behavior.

Observations of female behavior are now being linked with genetic analyses of mating patterns. For example, Kempenaers et al. (1992) used single locus markers to identify the sires of extra-pair offspring in blue tits (Parus caeruleus). These males had higher survival and produced more young that were recruited into the population than the putative fathers. Behavioral observations of females confirmed that females traveled to other males' territories for copulations. Similar patterns have been found in the related black-capped chickadee (Parus atricapillus; Smith 1988, Otter et al. 1994). In western populations of red-winged blackbirds (Agelaius phoeniceus), females also clearly initiate extra-pair matings with males, sometimes even gaining material benefits, which leads to about $35 \%$ of the offspring arising from EPFs (Gray 1996).

Frequent EPFs have stimulated several researchers to look more carefully at variation in female movement patterns and vocalizations during the fertilizable period. In chaffinches (Fringilla coelebs) and hooded warblers (Wilsonia citrina), some females move to or over territory boundaries between males, or produce conspicuous vocalizations that appear to attract males to them, during their fertilizable 
period (Sheldon 1994, Neudorf et al. 1997). These results suggest females have subtle behavioral tactics to manipulate their male mating partners.

Experimental approaches have also yielded interesting new insights about female behavior and paternity. In tree swallows, removals of male partners just after the start of egg-laying caused new males to associate with the female (Lifjeld \& Robertson 1992). Genetic analyses of paternity revealed that if females had eggs fertilized by an extra-pair male before removal, they were likely to have eggs sired by the replacement male after removal. Females that had only within-pair offspring before removal kept on producing eggs sired by the removed male after replacement. These results suggest that females can influence (via behavioral or physiological means) the sire of her offspring.

The intense interest in female behavior patterns has shifted the balance of focus in studies of mating patterns from males to females. This has dramatically increased the richness of hypotheses about mating interactions. However, every copulation requires a behavioral interaction between a male and a female, and hence is not under the exclusive control of either sex. Thus facile conclusions about the fitness consequences of particular female behavioral traits without factoring in the behavior of the opposite sex are likely to be quite misleading. Two competing hypotheses exist in every case of extrapair fertilization: either the female encouraged the mating and benefited from the event; or the event was costly to her, but preventing it from happening would have been even more costly. Detailed behavioral observations in some species reveal substantial variation in both male and female behaviors during extrapair events (e.g., red-winged blackbirds; Westneat 1992; house sparrows, Passer domesticus; Møller 1987a). These cases suggest to me that EPFs in any population might arise in a variety of ways. No study to date has documented the proportion of EPFs arising from female versus male pursuit. This is not surprising, given the difficulty in determining the behavioral routes to EPFs. My point here is to note that we know very little about the behavioral interactions leading to EPFs and the results of genetic studies have far outstripped our knowledge of these events. A central remaining unanswered question in the study of avian mating patterns is how EPFs emerge from diverse and often complex male-female interactions during mating. Answering this question will require a new level of integration between behavioral observations and the use of genetic markers.

\subsection{Paternity and Paternal Care}

A second important area of research stimulated (or re-stimulated) by the use of genetic markers is how paternity affects paternal behavior. The impact of paternity on paternal care was a logical extension of Hamilton's rule (Hamilton 1964), obliquely but not directly mentioned by Trivers (1972), and cited as a possible factor explaining paternal care patterns in fishes (Ridley 1978). Several models in the late 1970s-early 1980s seemed to debunk the idea that paternity affects paternal care (e.g., Maynard Smith 1978, Grafen 1980, Werren et al. 1981). These models noted that the selective forces acting males who have reduced paternity include the effects of paternity on the alternatives to providing paternal care (e.g., attracting additional mates or surviving until next season). If average paternity in the population is used in the model, then it affects these alternatives as much as reduces the benefits of care. Although many empiricists did not seem to accept these models (the effect of paternity on paternal care was often cited in papers on EPCs in birds; e.g., Frederick 1987, Møller 1988a), a theoretical justification for considering paternity which built upon the earlier models had not been presented. 
The use of genetic markers to uncover widespread and variable effects of multiple mating on paternity provided a strong justification for re-examining the effect of paternity on paternal care. In addition, conventional explanations of patterns of male care among species that invoked variation in social mating system (e.g., Silver et al. 1985) were not sufficient to explain diversity in parenting behavior. Some early thoughts on the consequences of multiple mating for females often included the potential cost of reduced male care (e.g., Westneat et al. 1990). Because the effect of paternity on paternal care was the original question that I sought to test in studying indigo buntings, I had been thinking casually about a theoretical basis for variation in the effect of paternity on paternal behavior. Conversations with Paul Sherman provided the catalyst to produce a more formal framework (Westneat \& Sherman 1993). Others researchers were coming to similar general conclusions through different routes (e.g., Whittingham et al. 1992, Xia 1992).

The results of this theoretical effort were fascinating, if a bit sobering. Paternity can be incorporated into life historical models of parental care (e.g., Winkler 1987), but exactly how it is incorporated dramatically affects its influence. None of the previous modeling efforts had been well informed by data on natural patterns of paternity. Paternity in natural populations is quite variable from one breeding episode to the next and one season to the next. So, the early models which assumed a constant paternity (e.g., Maynard Smith 1978, Grafen 1980) or which assumed that paternity only affected the current brood (e.g., Winkler 1987) seemed too simplistic. In addition, the level of information about paternity available to a male, and hence the scope for plasticity in responding to reduced paternity, also influences how paternity might affect paternal behavior (Westneat \& Sherman 1993).

The data on paternity and paternal care now available are equivocal (Wright 1998). In some case an effect is seen (e.g., Dixon et al. 1994, Weatherhead et al. 1994) but how those cases fit the new theory remain unclear because little is known about how males might detect reduced paternity in these populations. Other studies show no effect of paternity (e.g., Whittingham et al. 1993, Westneat 1995, Whittingham \& Lifjeld 1995, Wagner et al. 1996), but it is not clear that these constitute unequivocal tests of theory. In red-winged blackbirds, correlation tests reveal no relationship between paternity and male provisioning (Westneat 1995). Males appear to have minimal cues of paternity, a situation theory predicts should produce no effect of paternity (Westneat \& Sherman 1993). Yet, Weatherhead et al. (1994) found in another population that nest defense was correlated with paternity. At present, no clear reason for these differences in results has been found. Experimental studies might provide more compelling results, but those conducted to date suffer from uncertainty over whether or not the appropriate cue of paternity was manipulated (reviewed by Kempenaers \& Sheldon 1996, Wright 1998).

Clear tests of theory are likely to be difficult but not impossible to achieve (e.g., Kempenaers \& Sheldon 1996, Wright 1998). Careful study of the behavioral events leading to reduced paternity, with subsequent experimental manipulation of potential cues of those events, seem the best route. To date, only Davies' (1992) study of socially polyandrous dunnocks (Prunella modularis) has achieved this goal. Polyandrous male dunnocks clearly pay attention to mating access just before the first egg appears in the nest, as removals and egg manipulations reveal. Polyandrous dunnocks, however, are not representative of the many species of birds (and fish) in which brief liaisons outside of established longterm social bonds lead to reduced paternity. In these cases, the cues available to males about paternity could be much more subtle. Continued use of genetic tools combined with detailed behavioral 
observations in well-studied populations may yet provide the setting for revealing experiments about paternity and paternal care.

\subsection{Sexual selection on males}

The existence of such genetic tools as PCR-amplified microsatellites indicates how far we have come technically since Darwin's day, when little was known about the nature of heritability. And yet, still we are using these modern tools to answer a major question posed by Darwin (1871); that is, why do males often have such elaborated secondary sexual characteristics? Darwin's (1871) hypothesis was that such traits were favored in competition for mates, either through inter- or intra-sexual selection. A long-standing puzzle has been why socially monogamous animals, such as the indigo bunting, would nevertheless have considerable sexual dimorphism. The discovery of widespread EPFs reveals a potential arena for sexual selection in monogamous animals that was previously unknown. Genetic tools for analyzing patterns of matings thus seemed to offer additional insight into the process of sexual selection.

Oddly, however, the results of a variety of studies reveal no consistent pattern. EPFs have wildly variable effects on measures of the intensity of sexual selection on males (e.g., Møller 1998). In addition, associations between male traits and success at EPFs have been found in some species but not others. Finally, in no species has the exact mechanism of advantage of a secondary sexual trait been revealed. Several examples will illustrate this situation:

(1) In a series of correlational and experimental studies, Møller and colleagues have explored the selection on several male sexually dimorphic characters in the swallow (Hirundo rustica). Manipulation experiments revealed that the length and symmetry of male tail ornaments had significant effects on both pairing success (Møller 1994) and paternity (Saino et al. 1997). Correlational analyses have shown that paternity is related to both natural tail length and song rate, and that song rate has effects only for males with longer tails (Møller et al. 1998). Considerable evidence exists that both sets of traits reflect underlying quality because males with naturally longer tails have higher survival and produce offspring less susceptible to parasites (Møller 1994). These circumstances strongly suggest female choice for males with longer or more symmetrical tails. Yet, even in this well studied system, little specific information about how male traits modify female behavior is known. Alternative hypotheses based on the effects of male competitive interactions have not been directly considered and tested. In addition, tail elongation of birds in Canada resulted in reduced paternity (Smith et al. 1991), although paternity was positively correlated with natural tail-length. These results suggest that natural tail-length is correlated with another trait that affects male-female interactions over paternity rather than tail length per se having an influence.

(2) Red-winged blackbirds are extremely sexually dimorphic in size, plumage, and behavior. Many studies have sought to establish an association between aspects of sexual dimorphism and mating success, but have by and large failed (reviewed in Searcy \& Yasukawa 1995). Several studies of EPFs and male traits have followed these other studies in the hopes that EPFs would reveal the 'true' nature of sexual selection. EPFs, however, alter the intensity of sexual selection on males only slightly (e.g., Gibbs et al. 1990, Westneat 1993a, Weatherhead \& Boag 1997), and the largest contributor to variance in male success is still the number of social mates nesting on a male's territory (Webster et al. 1996, Weatherhead \& Boag 1997). Not surprisingly, few associations between male success and male 
traits have been found; Weatherhead \& Boag (1995) found that success at EPFs was correlated with male age, but not with body size, epaulet size or color, or any behavioral responses to male or female models. Behavioral data from some eastern populations suggests that females are not making overt choices among males, and that EPCs are gained opportunistically with relatively little direct male-male competition (Westneat 1992, 1993a, b; Weatherhead 1999), a situation in which variance in male secondary sexual characteristics might have little effect on mating success.

In western populations, females often pursue EPCs (Gray 1996). However, it is not clear they use any particular male trait on which to base their choice of partner. In fact, pursuit appears to gain females material and fertilization insurance benefits, which are not likely to be associated with any particular male secondary sexual trait. Hence, EPFs do not seem to explain dramatic sexual dimorphism in this species. However, several untested possibilities remain. Plumage manipulations are underway in a couple of populations, and this experimental approach may reveal more about the nature of selection on male traits than have correlational approaches. In addition, not all of these types of studies have been done in populations known to differ in other ways. Such replication might reveal different relationships between EPFs and sexual selection on male traits.

(3) Studies of EPFs in the great-reed warbler (Acrocephalus arundinaceus; Hasselquist et al. 1996), have revealed a fascinating relationship between male repertoire size and EPFs. EPFs, however, constitute just $3 \%$ of total fertilizations (Hasselquist et al. 1995), and so the intensity of sexual selection caused by EPFs cannot be very large. In addition, although circumstantial evidence suggests that females pursue EPCs in this species, it is not clear how they do so, nor how song repertoire is involved in the behavioral mechanics of female choice during EPCs.

(4) In the bluethroat (Luscinia s. svecica), the male ornament of the blue throat patch has been found to contain substantial reflectance in the ultraviolet spectrum (Johnsen et al. 1998). Experimental manipulation of this throat patch, either by blackening entirely or by use of a UV-only blocker produced effects on pairing success and success at fertilizing mates (Johnsen et al. 1998). In separate studies, female bluethroats were found to move about extensively before egg-laying (Smiseth \& Amundsen 1995); however, female pursuit of EPCs has not been directly demonstrated nor has the exact role of the blue throat of the male in the targeting of such pursuit been uncovered.

Some additional examples further illustrate the limits to our understanding of sexual selection in avian systems. Clear evidence of female pursuit of EPCs exists for the blue tit and black-capped chickadee; both species have little sexual dimorphism and there is no evidence that any dimorphic trait is involved in extra-pair choice (Kempenaers 1992, Otter et al. 1994, Boag this volume; although recent discovery of hidden sexual dimorphism via ultraviolet patterns of the blue crest in blue tits might change this situation; Hunt et al. 1998). Females also pursue EPCs in hooded warblers, yet no male sexually dimorphic trait has yet been linked to EPFs (Stutchbury et al. 1997). Results from pied flycatchers (Ficedula hypoleuca) are particularly confusing; results from a Finland population reveal no correlates between male plumage traits and EPFs (Rätti et al. 1995), whereas a study in Norway found that darker males (preferred by females as social mates, Saetre et al. 1994) actually had lower paternity than browner males (Lifjeld et al. 1997). Finally, those studies showing a relationship between male plumage traits and EPFs, such as in yellow warblers (Dendroica petechia; Yezerinac et al. 1995), yellowhammers (Emberiza citrinella; Sundberg \& Dixon 1996), and collared flycatchers (Ficedula albicollis; Sheldon \& Ellegren 1999) have not demonstrated how the trait is involved in male-male or 
male-female interactions over EPCs. Confusion about how multiple mating leads to sexual selection on males exists in other taxa as well (e.g., Gomendio et al. 1998).

Genetic tools have created a superb opportunity to understand sexual selection more completely, and yet, they seem to have raised more questions than they have answered. In particular, the basic question of whether or not sexual selection occurs via female choice or male-male competition is still largely unresolved. None of the studies described have eliminated the possibility that the focal male traits are involved in or correlated with success at male-male interactions over females. While female preferences are likely involved in many of these cases, because EPCs are quick and subtle, assessing the exact role of male traits in female choice versus male-male interactions is difficult. This limits our understanding of how evolution in these systems is actually proceeding. Again, future research will likely involve continued use of genetic markers combined with careful behavioral observations and astute experimental manipulations.

\subsection{Ecology of Mating Patterns}

The dominant paradigm of the field of behavioral ecology is that ecological parameters affect behavior. Indeed, an early, classic study of the ecology of behavior was that of Crook (1964), who established how food supply affected the mating systems of weaver finches. Ecological factors are a major underpinning of Emlen \& Oring's (1977) conceptual framework for understanding the evolution of mating systems. Aspects of ecology also should affect the behaviors that influence mating patterns (Westneat et al. 1990. These factors include density, breeding synchrony, the value of male parental care, and the distribution of key resources. Genetic tools have played an important role in exploring these ideas. The results of such studies, however, are mixed.

Density.- Early studies of EPCs in birds suggested that the greater the proximity of individuals, the higher the EPC rate (e.g., Birkhead 1978). Recent comparative studies of EPCs in birds support this idea (Møller \& Birkhead 1992, 1993). However, comparative studies of EPFs reveal that dispersed nesters tend to have higher rates of EPFs (Westneat \& Sherman 1997). Many (but not all) within-species studies show that EPFs increase with density. It is clear from this mixture of results that the effect of density is complicated, and may interact with other variables. Density should neither be invoked automatically as an important factor, nor dismissed. New theory specifying the exact mechanisms by which density influences extra-pair events seems needed. Such theory could lead to new, more sophisticated empirical studies, all of which would continue to make use of genetic markers.

Breeding synchrony.- The timing of breeding by females in a population has also been proposed as an important population factor influencing rates of EPFs. The initial idea was that synchrony would reduce EPFs because it would shift the operational sex ratio more toward 1:1 (Birkhead \& Biggins 1987, Westneat et al. 1990). This idea assumes that males pursue EPCs. In keeping with the growing emphasis on female pursuit, Stutchbury \& Morton (1995) subsequently suggested that synchrony might increase EPFs because it allowed females to compare more males. These divergent predictions have continued to be controversial (e.g., Stutchbury 1998a, Weatherhead \& Yezerinac 1998). Empirical tests, however, have been equivocal, with some cases showing little or no association between EPFs and synchrony (e.g., Dunn et al. 1994, Weatherhead 1997, Westneat \& Gray 1998), some showing a positive association (e.g., Stutchbury \& Morton 1995, Stutchbury 1998a) and some showing negative 
associations (e.g., Reyer et al. 1997). As appears to be the case with density, these results strongly suggest that the effects of breeding synchrony are contingent on other factors. More theoretical analysis of how synchrony might affect extra-pair events is needed, and that should stimulate further empirical studies involving the use of genetic markers.

Value of male care.- The harshness of the habitat will affect how valuable male parental care is to the survival of the offspring. A high value of male care should affect EPFs by (a) creating strong conflicting demands with the pursuit of EPCs, and (b) possibly (but see Westneat \& Sherman (1993) for exceptions) making the potential loss of that care as paternity declines a cost for females who engage in EPCs.

Few studies have tested these ideas. Comparative analyses have shown a relationship between paternity and paternal care (Møller \& Birkhead 1993b; Schwagmeyer et al. 1999), but the causal relationships are uncertain in these analyses. For example, we do not know if high paternity favors extensive male care, or if a high value of male care reduces the behaviors that lead to reduced paternity. In a within-species study of indigo buntings, I found evidence for a trade-off between EPCs and paternal care (Westneat 1988). All observed EPCs in this species consisted of males intruding into territories and initiating interactions with fertilizable females; hence male effort devoted to EPCs consists of foraying extensively off territory. These forays increase if nearby females are fertilizable. However, foray rates are at their peak during incubation, and decline during the nestling and fledgling periods as males begin spending more time near the nest and in some cases provisioning offspring. Conversely, Stutchbury (1998b) found no evidence that in hooded warblers, male forays conflicted with paternal effort. However, because male hooded warblers pursue EPCs both through foraying and attracting females to their own territories (Stutchbury et al. 1994), foray rates alone do not fully measure male mating effort.

Clearly, additional studies of the effect of habitat on male care and the effect of male care on EPCs need to be completed. These studies would usefully combine genetic analyses with behavioral observations, and perhaps some focused experimental manipulations.

Habitat type.- A study of EPFs in white-crowned sparrows (Zonotrichia leucophrys) lead to the suggestion that habitat type might influence EPFs (Sherman \& Morton 1988). Complex habitats, in which territory boundaries cannot be seen or patrolled easily from one central location, or in which following the female might be difficult, could create conflicting demands on males. The prediction was that EPF frequency would be greater in such visually occluded habitats, and yet no published study to date has examined this idea.

One currently unpublished study appears to support this idea. In Wilson's warblers (Wilsonia pusilla), EPFs were higher in territories having denser stands of willows than in more open territories (Bereson \& Fleischer, pers. com.). Here again, additional studies combining habitat measures and genetic analyses are needed.

Resource distribution and mate-guarding.- In a comparative study of copulation and mateguarding behavior, Birkhead et al. (1987) found that colonial species guarded mates less intensely than dispersed nesters. An explanation for this behavior was that many colonial nesters, such as seabirds and wading birds, must guard the nest site during the fertilizable period. Because food, water, and nesting material are often far from nest-sites, this produces tremendous conflicting demands on mate-guarding. Two possible compensating paternity guards are frequent copulation (Birkhead \& Møller 1992) and the timing of copulation (Hogg 1988). 
Few studies have experimentally tested if the distribution of resources conflicts with mateguarding and affects mating patterns. I found an ideal system to test this idea in red-winged blackbirds (Westneat 1992, 1993b, 1994). Males guard mates, but do so somewhat loosely compared to many other species. However, they can respond to intruders and keep females in sight a large portion of the time by sitting on a few exposed perches when their territories are free of brushy habitat. But, males do leave their territories regularly, and it is during these absences that the majority of EPCs occur. Shortterm removals of territorial resident males confirmed that their presence prevents intrusions and EPC attempts by neighboring males, that females do not leave when males are absent, and that male presence increases paternity (Westneat 1994). These results raised the question of why males leave their territories at all during the fertilizable period. Because males were often seen foraging on these trips away, a logical hypothesis was that food supplies were insufficient on the territory and better elsewhere. Experimental supplements of food on territories lead to a reduced number of trips away, and higher paternity (Westneat 1994).

In sum, genetic tools have stimulated many studies linking ecology with mating patterns. Nevertheless, considerably more work is needed if general principles linking ecology with mating are to be revealed. Few experimental studies have been done that manipulate a key resource and measure the impact using genetic tools. There are many opportunities for additional studies of this sort.

\section{Documenting diversity or confronting complexity?}

Genetic tools have stimulated many new routes of investigation into mating patterns, particularly in birds but also in other taxa. These areas of investigation all have arisen and progressed quickly because of the new insights that genetic markers can provide, and many questions remain to be answered, all of which will rely extensively (but not exclusively) on the use of genetic markers. The role of molecular tools will only grow as new techniques and more powerful markers make uncovering mating patterns easier.

However, as the new techniques have opened a number of new avenues of research, they have also created a problem. This problem is most clearly seen in birds. What used to be a taxa with a fairly well explained set of mating behaviors is now one in which every species, and in some cases different populations within species, has a different suite of mating behaviors leading to a different mating pattern. A hint of this diversity can be seen by mapping EPF frequencies onto a phylogeny of birds (Fig.2).

Of immediate note in Fig. 2 is the difference between passerine and non-passerine birds. Nonpasserines are variable, but the passerines exhibit even more diversity. Take, for example, the swallows. EPF frequencies range from a low of $4 \%$ to a high of over $50 \%$. Barn swallows are obviously sexually selected, with sexually dimorphic traits, yet they have lower frequencies of these matings than do tree swallows which appear sexually monomorphic. Tree swallows and cliff swallows are very similar in many respects: they are at least semi-colonial, socially monogamous, and have extensive biparental care. Yet in terms of EPF frequencies they are at opposite ends of the range. 


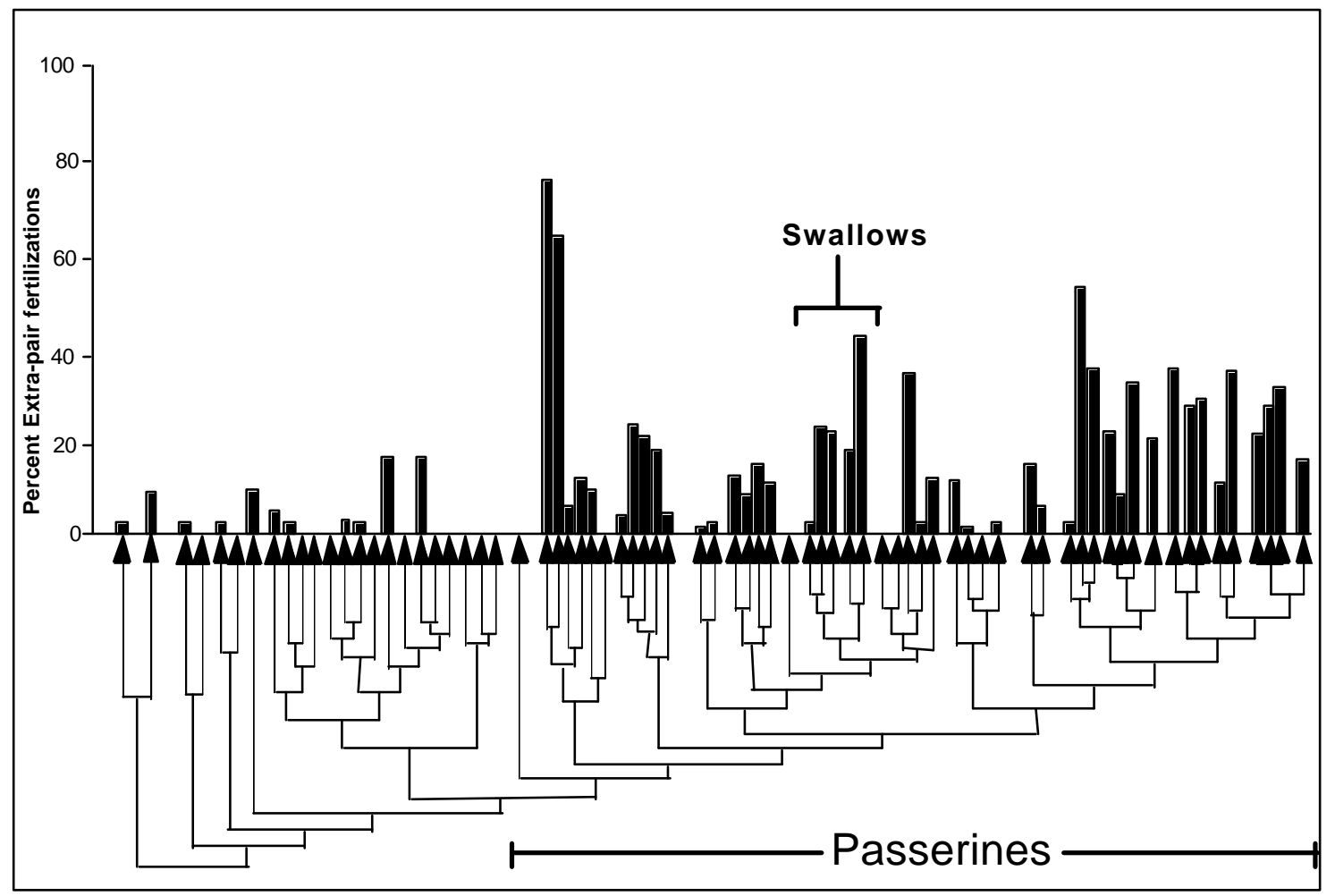

Figure 2. Histogram of EPF frequencies mapped onto a phylogeny of birds showing incredible diversity within and among taxa. Data from Westneat \& Sherman (1997).

Taxonomic variation in raw EPF frequencies is just part of the story. Substantial variation in extra-pair behavior exists, but does not, on the surface, correspond well with raw EPF frequencies. For example, male mate-guarding behavior varies widely between species. In colonial seabirds, it is very low and extra-pair paternity is low (Birkhead et al. 1987). In tree swallows, male guarding is also weak, yet EPP is high (Leffelaar \& Robertson 1984, Lifjeld et al. 1993). In barn swallows, mate guarding is much stronger, and EPP is lower (Møller 1994, Saino et al. 1997). In bluethroats, bright males do not guard their females as closely as duller males do, yet their paternity is higher (Johnsen et al. 1998).

Female behavior also varies among species. In blue tits, females fly off their mate's territory and solicit EPCs with nearby males (Kempenaers et al. 1992). In several other species, such as yellow warblers (Yezerinac \& Weatherhead 1997), indigo buntings (Westneat 1987b), and eastern populations of red-winged blackbirds (Westneat 1992), female pursuit is at least rare, and yet the rates of extra-pair paternity are considerably higher than that found in blue tits. Nonetheless, the highest rates of EPFs yet found occur in the superb fairy wren, in which females often pursue EPCs from nearby males (Mulder et al. 1994).

Substantial variation also exists between populations within the same species. Pied flycatchers from Sweden have about 25\% of their offspring from EPFs (Gelter \& Tegelström 1992), whereas a population in nearby Norway found only 4\% EPFs (Lifjeld et al. 1991). In eastern populations of redwinged blackbirds, females do not pursue copulations with extra-pair males, but respond variably to their courtship attempts (Westneat 1992). In the west, females often leave their mate's territory and go to other males to solicit copulations (Gray 1996). In bearded tits (Panurus biarmicus), females achieve 
EPCs through spectacular female initiated chases in which a group of males flies after the fleeing female (Hoi \& Hoi-Leitner 1997). Rates of EPFs are greater in colonies, presumably because females have more choice of genetic mates in colonies. By contrast, female house sparrows are involved in EPCs both through solicitation and through aggressive group chases initiated by males (Møller 1987a, Westneat, pers obs.). However, density appears not to be a major factor in the rates of EPFs (unpublished data), and it is unclear what proportion of EPFs come from solicited versus aggressive copulations.

These results from birds parallel similar findings in other taxa. They serve to reemphasize the fascinating new developments that genetic tools have stimulated. There is a great deal of excitement, and many researchers are making great strides in understanding their own system. Alternative hypotheses are being tested and we are repeatedly confirming the power of the adaptive paradigm. And yet, personally, I am discontented. Although it is interesting and important to develop a fuller understanding of each specific species, in doing so we do not move much closer to answering two important questions: (1) Why are different species so different? and

(2) Can we make sense of this diversity and develop approaches that directly confront the complexity of mating system evolution?

\section{Interacting phenotypes and social selection: A new framework for studying mating interactions}

Most theory about mating patterns seeks to explain diversity (e.g., Orians 1969; Emlen \& Oring 1977; Wittenberger 1979; Thornhill \& Alcock 1983; Davies 1991; Reynolds 1996; Brown et al. 1997). Indeed, the standard ideas of mating systems (e.g., Trivers 1972; Emlen \& Oring 1977; Maynard Smith 1977) provided general insights (e.g., ideas on conflicting demands, the ecological basis of mating behavior) and methods of approach (e.g., the concept of evolutionarily stable strategies, ESS) that have produced most of the advances in the study of mating patterns made to date. Those core ideas will also be important in future explanations of diversity in mating patterns, but the conceptual framework outlined in these earlier views is not sufficient. For example, the two factors contributing to the environmental potential for polygamy, the value of male parental care and the distribution of mates in space and time (Emlen \& Oring 1977), while useful generally, cannot by themselves explain the diversity in mating patterns. An example illustrating this can be found in the swallows; EPF rates in cliff swallows (Hirundo pyrrhonota), a colonial species with biparental care, are substantially lower (2\%; Brown \& Brown 1988) than the rate found in tree swallows (44\%; Lifjeld et al. 1993), a semi-colonial species with biparental care. Apparent oddities like this seem to be the norm, and need to be explained.

Earlier theory included, but did not fully develop, the selective forces acting on both sexes. Emlen \& Oring's (1977) framework, for example, started with resource distribution, which influences the distribution of females, which then affects the distribution of males. This is a linear view of malefemale interactions, whereas the research conducted over the past 20 years has revealed that mating interactions are more dynamic. The flexible mating patterns exhibited by dunnocks are a case in point (Davies 1992); both male and female behavior depend on resource distribution, the behavior of others of the same sex, and the behavior of the opposite sex. This dynamism is the focus of new versions of mating theory presented by Davies (1991), Reynolds (1996), and Brown et al. (1997), which have as a central feature, reproductive conflict between the sexes (Figure 3). Different patterns of male and female 
associations and copulations arise out of how ecological factors influence the selective consequences of mating interactions (e.g., Westneat et al. 1990). This core idea sets the stage for a more complete explanation of diversity in mating patterns.

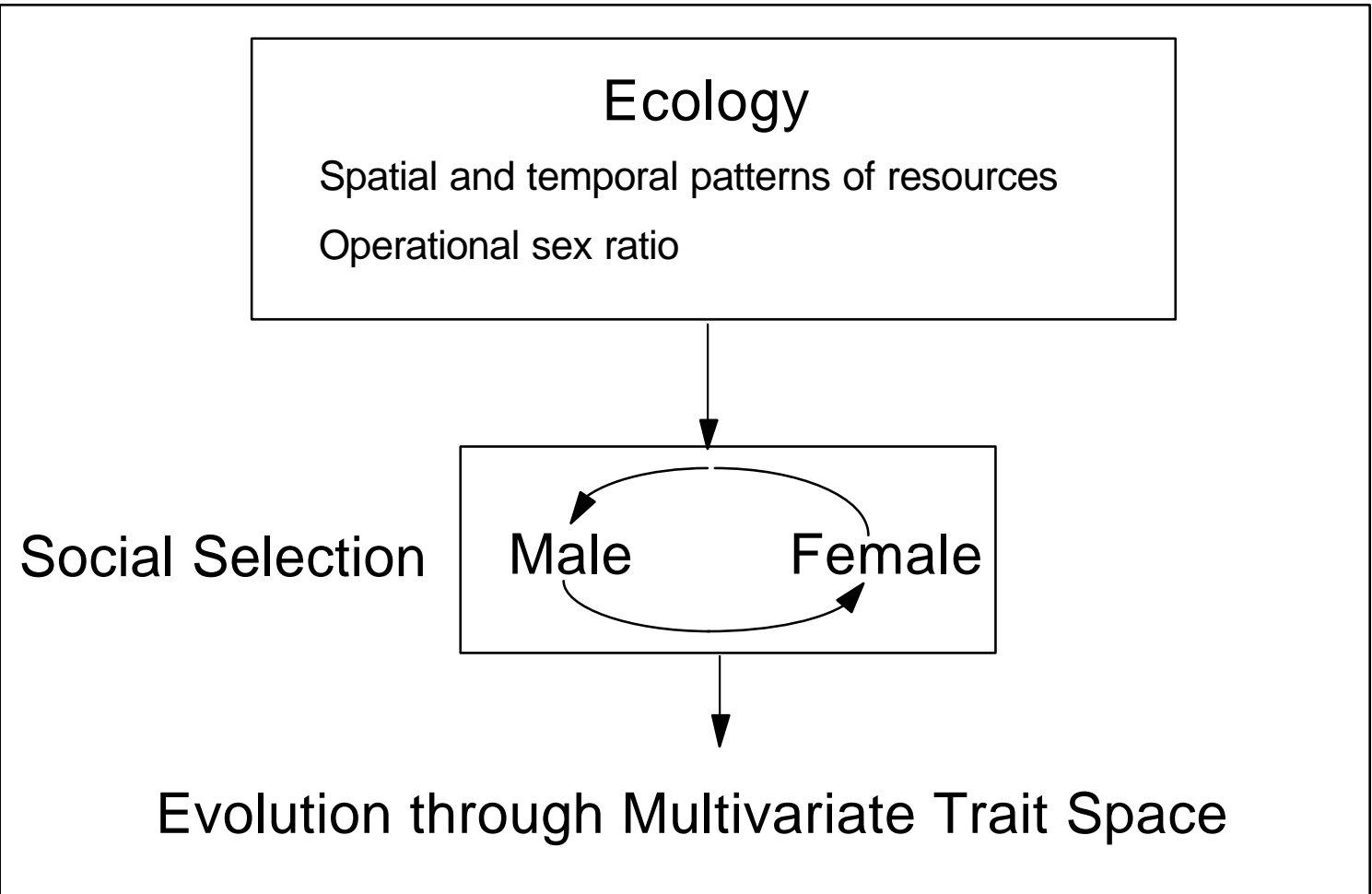

Figure 3. General outline of the evolution of mating patterns. Ecological factors (sensu Emlen \& Oring 1977) influence dynamic interactions between the sexes (Davies 1991, Reynolds 1996, Brown et al. 1997), which create selection forces driving evolution of traits related to mating.

Although they are a step forward, the schemes of Davies (1991), Reynolds (1996), and Brown (1997) have important limitations. They provide useful verbal images of key concepts like sexual conflict, but do not contain clearly defined, operational definitions. Such definitions are important for generating a quantitative theory with directly measurable variables (see also Arnold \& Duvall 1994). Analyses of mating interactions using game theory (e.g., Parker 1979) have more explicitly defined the influence of one sex on the fitness of another. Thus game theory could be used to expand conceptual frameworks that have dynamic interactions between the sexes at their core. Indeed, game theoretical approaches have lead to a number of advances in specific systems (see Szekely et al., this volume). However, game theoretic approaches also have their limitations. One in particular is that game theory makes some simplifying assumptions about the underlying genetics of the traits of interest (Moore \& Boake 1994). Alternative strategies are often viewed as alleles at a locus, and more complex influences on traits such a genetic correlations or gene by environment interactions have not yet been widely incorporated. Another potential limitation is that game-theoretic analyses specify the set of alternative strategies initially and analyze how selection might shape the organism's behavior given that strategy set. This a priori setting of alternatives can create some boundaries to considering all the possible selective consequences of social interactions, as I will show below. 
In the last part of this chapter, I present a framework for explaining diversity that retains much of earlier conceptual ideas and the spirit of game theory analyses, but incorporates more quantitative approaches to selection and to genetics. My overall thesis is that diversity in mating patterns arises from the confluence of three forces: (1) variation in ecology which influences the selective consequences of male-female interactions, (2) the specific ways social interactions lead to selection, creating pressure for evolutionary change, and (3) the particular genetic structure of the relevant traits in that population at that time, which affects the evolutionary response to selection. In other words, I want to integrate complexity in selection pressures and idiosyncratic aspects of the genetic structure of the relevant traits in a population, in the hopes that this may provide some new insights about diversity in mating patterns. This conceptual framework extends earlier ideas on the ecology of mating patterns, is compatible with game-theoretic approaches to male-female mating interactions, provides new insights into the dynamic nature of those interactions, suggests quantitative measures of key events, and easily integrates with a genetic approach to evolution.

\subsection{A selection theory definition of sexual conflict and cooperation}

Sexual conflict is a central aspect of most current views of mating systems (e.g., Davies 1991; Reynolds 1996; Brown et al. 1997). Although the focus on conflict has perhaps overshadowed the still important role of cooperation, both are part of the same issue; how the reproductive interests of the two players, male and female, in any reproductive bout either diverge or coincide. While generally appealing, the phrase "divergent (or coincident) reproductive interests" is in my view too vague to generate specific, testable and measurable concepts about conflict and cooperation. ESS theory (e.g., Parker 1979, 1984) on sexual conflict has produced a more rigorous definition of conflict. Parker (1979) for example, defined conflict as, "when an advantageous character in (one sex) conveys a selective disadvantage to a character in (the other sex)". However, I would suggest that this definition reflects a potential problem with ESS approaches: it immediately specifies two traits, which can constrain one's perspective to some degree. To see how, I offer a slightly different definition that arises from social selection theory (Wolf et al. in press) and extends previous attempts to link selection theory with ideas on mating systems (Arnold \& Duvall 1994).

Selection theory focuses on defining components of fitness and linking variation in those components with phenotypic traits to better understand the selection acting on those traits (e.g., Arnold $\&$ Wade 1984). Directional selection on a trait is defined as the partial regression of fitness on a trait, which is the slope of the line relating fitness to trait values. Figure 4A presents a hypothetical example illustrating a selection gradient. The selection gradient is an important component to understanding potential evolution of a trait, yet it may not explain all or even most of the variation in fitness. Visually, path analysis (Wright 1968) provides a useful way of organizing the relationships between several key variables involved in selection and corresponding evolutionary responses (Fig. 4B). Variation in fitness can be explained in part by variation in some trait (e.g., Fig. 4A)--this gradient is the path linking variation in phenotype $(\mathrm{P})$ with variation in fitness $(\mathrm{w})$. However, not all the points in Fig. 4A are exactly on the gradient line. Residual variation in fitness exists. Some of this residual variation may be due to selection on other traits that might or might not be correlated with the focal trait. If we assume that those sources are not involved, then one interesting source of residual variation comes from the environment (e.g., Rausher 1992). This creates a second path to fitness from the environment (Figure 4B). Normally, 
such variation is ignored because it is usually not relevant to the strength of selection on the focal trait of interest. However, any variation in fitness is an opportunity for selection (Crow 1958). Hence this environmental effect on fitness could be very important.

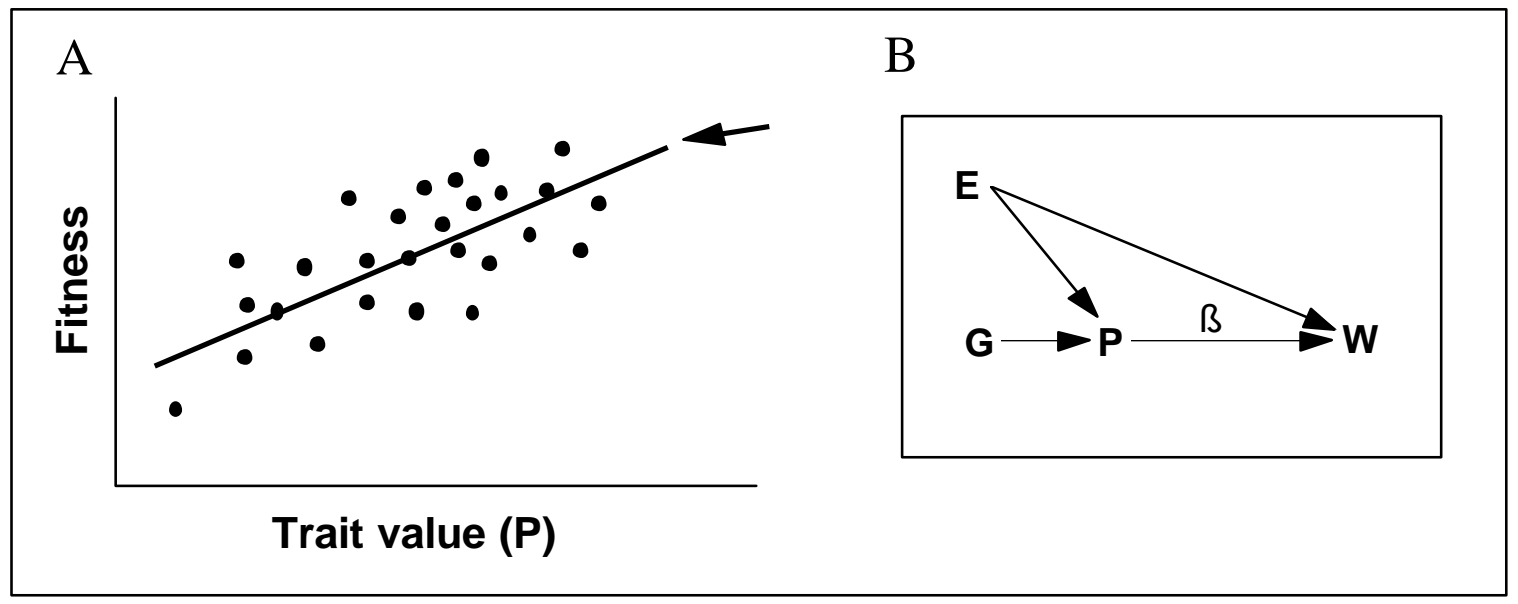

Figure 4. A) Hypothetical dataset showing a relationship between trait value and fitness. The slope of the least squares regression is the selection gradient (B). B) Path diagram illustrating causal links between additive genetic variation (a) affecting phenotypic variation (P), environmental variation (e) affecting both phenotypic variation and fitness variation $(\mathrm{W})$, and phenotypic variation affecting fitness variation, which is the selection gradient $(B)$.

One component of an individual's environment is the phenotype of other individuals with whom interactions occur. Variation in the phenotypes of interactants is a component of the environmental effect on fitness variation. Consider, for example, the trait of male display rate. If more display leads to more matings, then there is a positive selection gradient on male display. However, most likely there will be residual variation in the number of matings obtained which is not explained by display rate. One possible source of this residual variation is variation among females in their preference for display rate and/or which females are encountered by which males. These type of effects are illustrated in Fig. 4B as a path from $\mathrm{E}$ to $\mathrm{w}$, were $\mathrm{E}$ contains the variation in female preferences.

We can also account for this environmental effect in another way. Variation in female preferences will have an effect on female fitness, producing a selection gradient in females. Such variation in preferences also affects male fitness. Variation in fitness due to social interactants has been termed social selection (e.g., Crook 1972; West-Eberhard 1979, 1983; Wolf et al. in press). Such influences can be portrayed in a manner similar to that of the selection gradient (Figure 5A, B). This produces a partial regression coefficient (gradient) of fitness on the trait of the social partner. While mathematically identical to a selection gradient, this relationship does not describe selection, because the fitness value and trait value are not tied to the same individual. Rather this gradient measures the impact of trait values of mating partners on the focal individual's fitness, and hence describes a component of residual variation in fitness that is an opportunity for selection on the focal individual. In figure $5 \mathrm{C}$, this is represented as a path from the male phenotype to female fitness. 


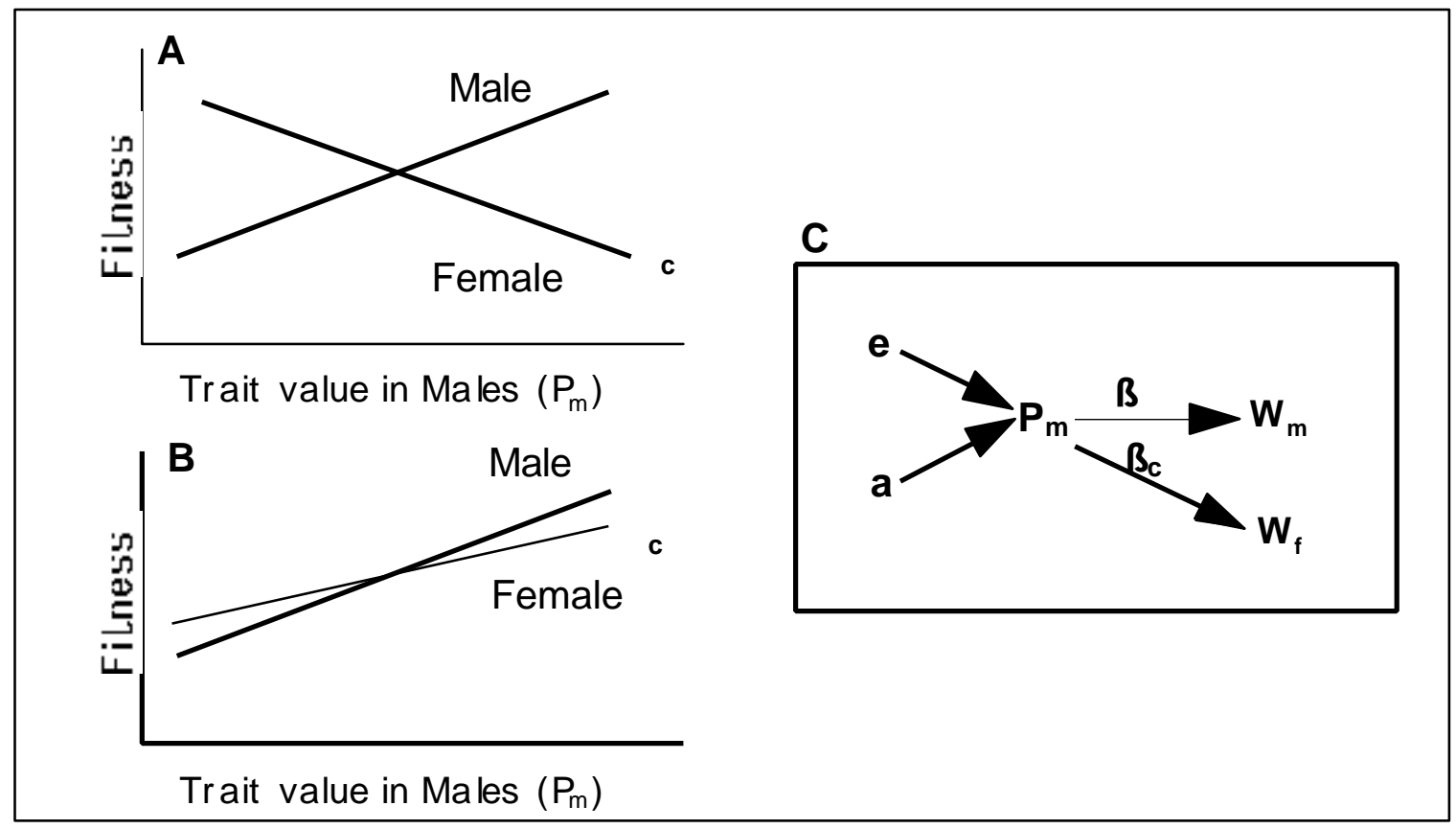

Figure 5. A) Graph of the effect of a trait in males on male fitness (producing selection gradient $\beta$ ) and on the fitness of female mating partners. The opposite slope of this latter gradient from the slope of the selection gradient makes this a case of conflict, and describes an opportunity for selection on females caused by the variation in the male trait. B) Similar graph as in (A), but the effect of the male trait on female fitness has the same slope as the selection gradient on males, producing an opportunity for selection via cooperation. C) Path diagram illustrating the linkages between environmental variation $(e)$, genetic variation $(a)$, male phenotype $\left(P_{m}\right)$, and male $\left(W_{m}\right)$ and female $\left(W_{f}\right)$ fitness. The path between $P_{m}$ and $W_{m}$ represents the selection gradient (B) and the path between $P_{m}$ and $W_{f}$ represents the conflict or cooperation gradient $\left(\beta_{\mathrm{c}}\right)$.

This approach leads to an explicitly quantitative definition of sexual conflict. Sexual conflict is the extent to which the opportunity gradient linking a focal trait in one sex to the fitness of the other sex is of opposite slope from the selection gradient on the focal trait. Conversely, if the opportunity gradient has a similar slope as the selection gradient, then sexual cooperation exists. Under this framework, sexual conflict (or cooperation) is a measurable aspect of the opportunity for selection created by variation in trait values of mating partners in the local population. This definition of sexual conflict retains elements of previous definitions (e.g., Parker 1979; Davies 1992), but differs in that it is a result of a single trait in one sex and is explicitly quantifiable. It also separates out questions about the presence and strength of conflict from the possible responses that might evolve.

Conflict and cooperation are interesting because they affect the evolution of traits in the other sex. This happens because the opportunity gradients contribute to variation in fitness, which then can produce actual selection gradients on any response trait that modifies the effect of the original trait. Figure 6A illustrates one possible relationship where a conflict gradient influences a selection gradient on a response trait. An increase in the male trait (point 1 to point 2) produces a reduction in female fitness. Females, however, have a trait which is selected against (because of a cost) at low values of the male trait, but is favorable under high values of the male trait. 


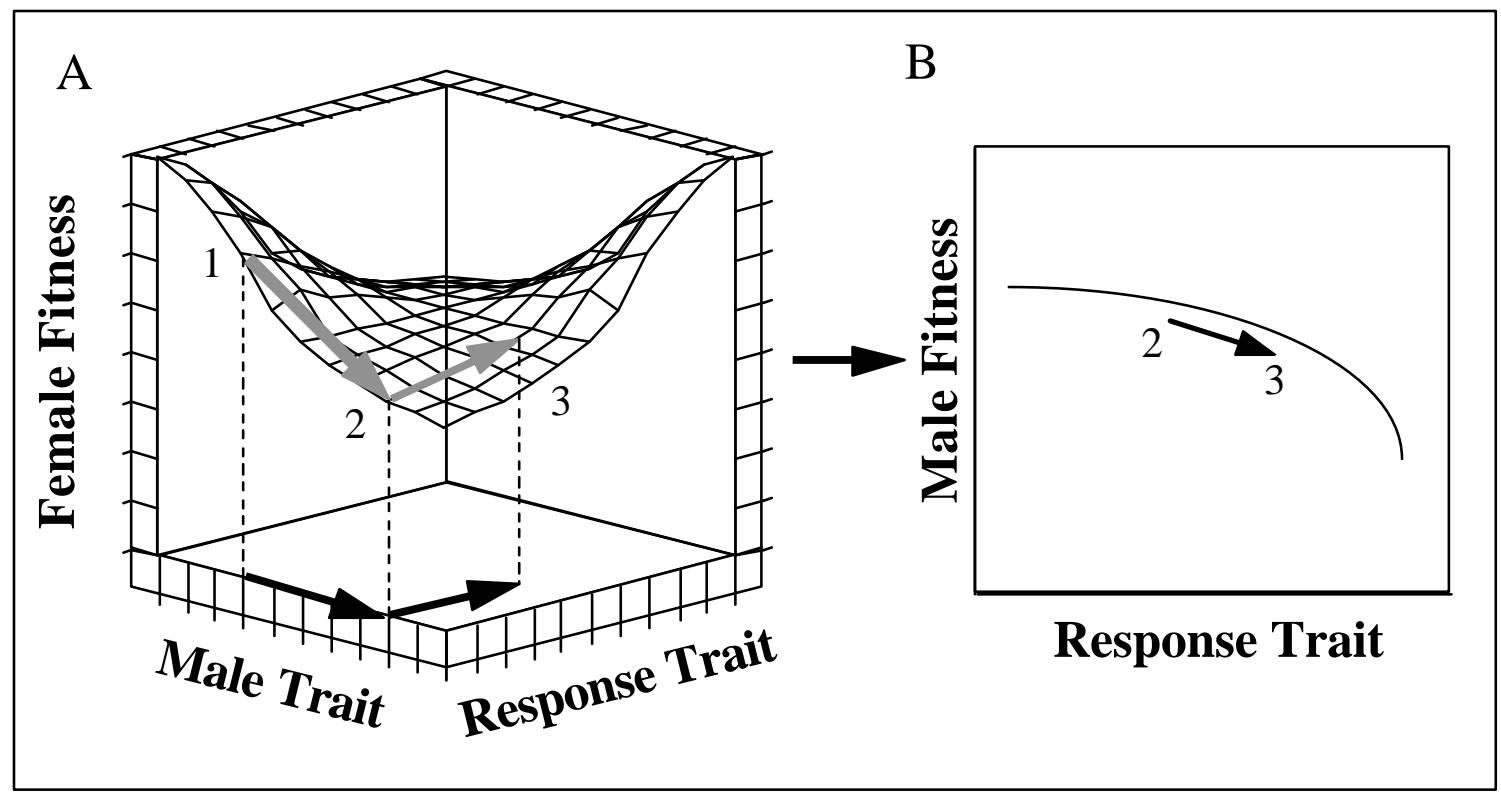

Figure 6. A) Three-dimensional fitness plane showing a conflict gradient relating female fitness and a male trait. The shape of this gradient depends on the value of a response trait in females. When that trait is at zero, selection favors an increase in the male trait (point 1 to point 2). If variation in the female response trait exists, then as evolution proceeds toward point 2 and the conflict gradient on females converts to an actual selection gradient on the female response trait, favoring evolution to point 3. Depending on the distributions of phenotypic values and the genetics underlying those values, the actual trajectory of the population might be a curved line from 1 to 3 bending toward point 2. B) Effect of female response trait on male fitness. As the response trait in females evolves as shown in (A) and females exist along the range of values from point 2 to point 3 , then males experience a conflict gradient. This would, in turn, create an opportunity for selection on a counter-response.

Many different traits could respond to conflict (or cooperation) gradients. These responses can be broadly organized into three categories. One possibility is choice; an individual could form preferences for members of the opposite sex that have trait values that improve fitness rather than decrease it. Female choice for males that are likely to provide parental care, such as female avoidance of already paired males in pied flycatchers (e.g., Alatalo et al. 1981; Dale \& Slagsvold 1994) is one such example. The conflict gradient might also lead to selection for manipulation, such as deceit, force, or traits that alter the conditions for the mating partner. Cooperative manipulation would be possible if a beneficial gradient existed. Finally, either conflict or cooperation gradients might favor traits that serve to compensate for the effect of the trait value in the partner. For example, reduced clutch size might compensate somewhat for the effects of reduced paternal care (e.g., Møller 1994).

The evolution of a response trait is likely to produce a new conflict gradient acting on the mating partner (Figure 6B). This framework thus produces the same type of outcome as ESS theory -- that is, sexual conflict could lead to an evolutionary arms race (e.g., Dawkins 1976). However, viewing conflict as an opportunity for selection, rather than actual selection as does Parker (1979), leads to a framework that inherently suggests alternative evolutionary results. An array of traits could evolve in response to conflict (possibly several simultaneously), and hence there is an array of possible ESS games that might exist. In turn, once a particular response trait evolves, a new array of alternative counter-responses might be favored. The evolutionary outcome of this could be viewed as a cascade (Figure 7). 


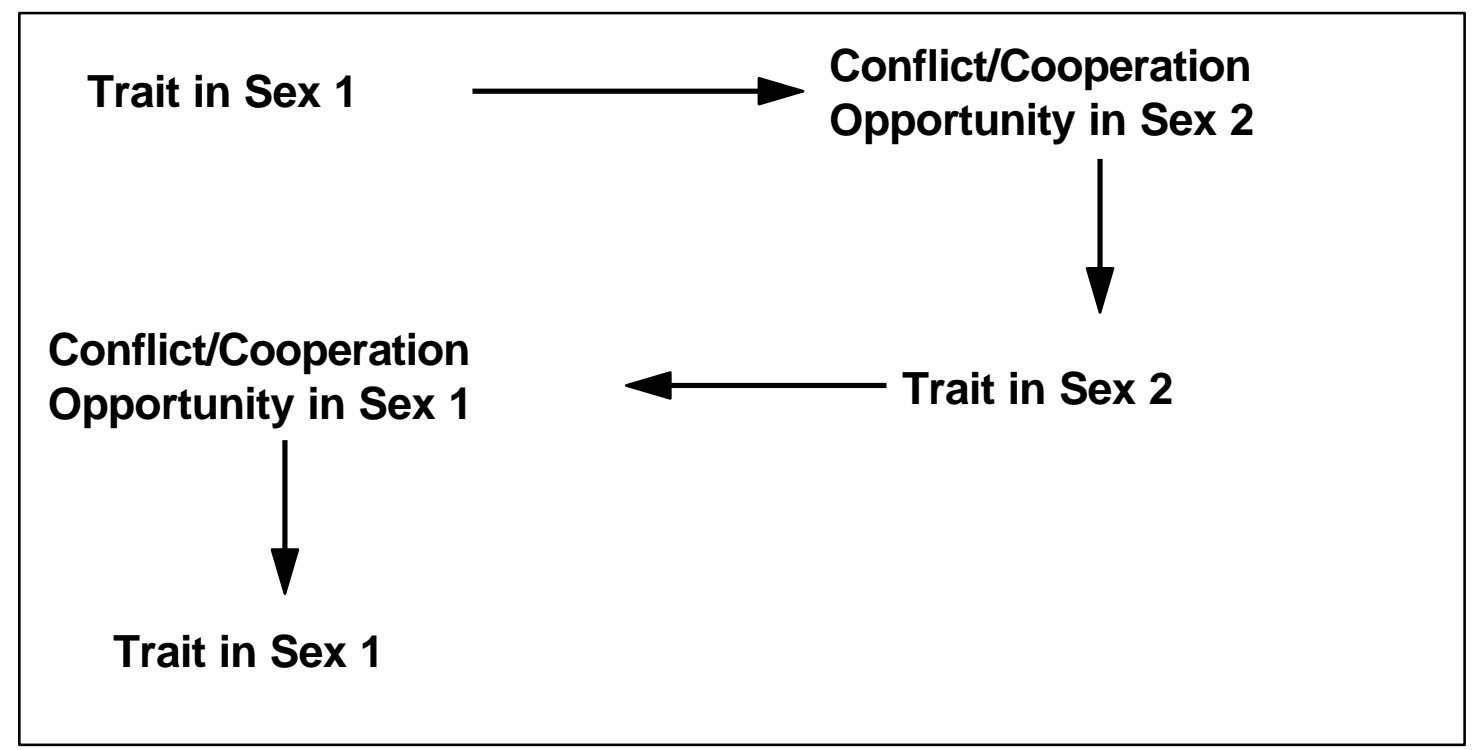

Figure 7. Diagram of evolutionary cascade arising from conflict or cooperation gradients. Opportunity for selection caused by one trait leads to evolution of a response trait, which in turn creates a new opportunity for selection, driving the evolution of a new response trait. Such cascades seem more likely to result from conflict than cooperation, but both types of gradients could lead to unique evolutionary sequences.

A brief description of the pied flycatcher illustrates one possible example of an evolutionary cascade. Female pied flycatchers benefit when males provide parental care, whereas males benefit by being polygynous, in which case they do not provide care to the second mate (Alatalo et al. 1981). Hence, selection favors attracting a second female and reducing care in males, but this reduced care should create a conflict gradient on females that might pair with an already paired male; those that pair with already paired males will have lower fitness than those that pair with unmated males. One potential response trait that might have evolved is choice; indeed, female pied flycatchers avoid males who already have a mate (e.g., Dale \& Slagsvold 1994). However, such choice is detrimental to males who might have been polygynous in its absence. Thus variation in the strength of the preference against paired males might have created a conflict gradient on males. A possible response for males, favored by this conflict gradient induced by female preference, might have been manipulation. Two possible manipulative responses have been suggested; deceit (e.g., fooling females into thinking they are unpaired by defending a second territory some distance from the first, e.g., Alatalo et al. 1981; Searcy et al. 1991) or altering conditions (e.g., by defending two territories males make it hard for females to assess male mating status at a time when delays to breeding might be more costly to females than settling as a secondary female, Stenmark et al. 1988; Dale \& Slagsvold 1994).

A conflict gradient view of pied flycatchers provides a coherent framework for understanding the studies that have been done on this species to date. It also provides a structure for analyzing and testing alternative hypotheses about this particular evolutionary cascade. Although we already know a great deal about pied flycatchers, some key elements of how they might have evolved have yet to be tested. A framework incorporating social selection identifies some alternatives that have yet to be considered. For example, three aspects of this system have yet to be fully explored: (1) the level of 
variation in female preference against already paired males, (2) the strength of the selection gradient for that trait, and (3) the steepness of the conflict gradient in males induced by female preferences. In addition, although a few aspects of female responses to male polyterritoriality have been examined (e.g., Dale \& Stenmark 1994), no one has yet assessed in a systematic way the possible conflict-induced selection on variation in possible female responses. Finally, the cascade scenario is merely a compelling hypothesis. A more complete test of it would examine the prediction that the cascade would differ if subtle differences in starting conditions (e.g., the value of male parental care) existed. This suggests that a search for populations with differences in the value of paternal care, and subsequent measurement of the selection and conflict gradients for the relevant male and female traits, might be illuminating.

Explaining differences among populations and species remains the central challenge to any framework of mating patterns. The idea of social selection leads to a general theory for diversity. Conflict (or sometimes cooperation) results in selection favoring a response, which could be any of a number of different traits. Which response actually evolves may depend on many factors. Thus, only slight differences between two populations could lead to dramatically different evolutionary trajectories, which eventually could lead to large differences in traits. If so, then to fully understand diversity in mating patterns, we must explore the potential causes of initial divergence and the processes affecting evolutionary cascades from a comparative perspective. To do this, we need a conceptual framework that links the idea of social selection with a variety of ecological and evolutionary factors that might influence the initial directions such cascades take.

\subsection{Genetics and the Evolution of Mating Interactions}

One possible explanation for why two populations might diverge is that slight differences in ecological factors or social situations create different selection pressures. Different possible response traits might differ among populations in their abilities to offset the reduction in fitness due to a partner's trait. In other words, the selective landscape as depicted in Fig. 6A might differ in different populations, so divergence in traits between populations would have a directly adaptive explanation. In many respects, this idea is the same as that contained in the theory of Emlen and Oring (1977) and successors (e.g., Davies 1991, Reynolds 1996, Brown et al. 1997). To test it, researchers would need to measure selection and conflict gradients in both sexes in both populations, and establish ecological reasons for differences between the populations in selection and conflict/cooperation gradients.

An alternative, but not mutually exclusive, hypothesis is that initial divergence is more a function of constraints. That is, some potential response traits might have reduced genetic variation, or might be genetically correlated with some other trait. Why these differences between populations would have occurred may be difficult to determine, as they could arise either through adaptive processes (selection on genetic correlations or selection favoring different dispersal behaviors which lead to differences in gene flow) or non-adaptive ones (e.g., genetic drift). However, once established, such differences in starting conditions could influence which traits evolve. That is, despite selection favoring their evolution, some responses evolve more slowly or in a different direction than an alternative response. While any response that does evolve is adaptive, the divergence between populations might not have a directly adaptive explanation, but rather could be due to differences in the genetic structure of the traits.

Lack of genetic variation or genetic correlations between traits are standard issues in quantitative genetics (e.g., Arnold 1994), and have been applied to some degree to the study of sexual 
behavior (e.g., Heisler 1994; Hedrick 1994). However, few studies of male-female conflict have employed a quantitative genetic approach. ESS approaches to conflict have been extremely useful in exploring the selective dynamics of conflict, but have made very simplifying genetic assumptions (Moore $\&$ Boake 1994). Thus, we know very little about how genetics might affect the evolutionary dynamics of male-female interactions. This is an area that clearly needs more theoretical and empirical development. Here, I will move on to describe a recent advance in quantitative genetics that has some fascinating implications for understanding evolutionary cascades in mating interactions.

I have already taken advantage of the well-established idea that the traits expressed by social partners affect both the bearer's and the partner's fitness. However, the traits of interactants also influence the partner's phenotype. Take, for example, the act of copulation, which is a critical event producing mating patterns. Neither the male nor the female can exhibit copulation on their own. Hence the trait can only be expressed when the partner's phenotype is appropriate. Other states that we might want to treat as traits, which also depend on the phenotypes of other individuals and affect mating patterns, are courtship sequences, dominance, territoriality, aggression, persistence, and resistance. A key component of all of these is that the phenotype of the interactant is a part of the environmental influence on the focal individual's phenotype. More interestingly, however, is that this component of the environment has a genetic basis and can evolve (Moore et al. 1997).

The evolutionary analysis of such between-individual effects of phenotype was explored in general terms by Dawkins (1982). He described both the selective and the phenotypic effects of some phenotypes in his phrase 'extended phenotype'. Recently, the specific effect of genetic influences on phenotypes in another individual, named "indirect genetic effects" (Wolf et al. 1998), has been incorporated into a quantitative genetic framework. Conventional maternal effects (the effect of a parent on the phenotype of the offspring; Cheverud \& Moore 1994) are an example of these types of phenotype interactions, but any interaction between conspecifics could also produce indirect genetic effects (Moore et al. 1997).

Figure 8 illustrates the general relationship between the phenotypic variance of the focal trait and direct and indirect genetic variance. Mathematically, the typical equation (ignoring covariances) for phenotypic variance $\left(\mathrm{z}_{1}\right)$ is

$$
\mathrm{z}_{1}=\mathrm{a}_{1}+\mathrm{e}_{1},
$$

where $a_{1}$ is the addditive genetic variance and $e_{1}$ is residual variation due to the environment. Moore et al (1997) modify equation (1) by separating out that component of the environment which consists of phenotypes in other individuals, or

$$
\mathrm{z}_{1}=\mathrm{a}_{1}+\mathrm{e}_{\mathrm{r} 1}+\mathrm{e}_{\mathrm{z} 2}
$$

where $\mathrm{e}_{\mathrm{r} 1}=$ residual environmental variance, $\mathrm{e}_{\mathrm{z2}}=¥_{12} \mathrm{z}_{2}$ and $¥_{12}$ is the slope of the line (path coefficient) that describes how $\mathrm{Z}_{1}$ changes as a result of interacting with $\mathrm{z}_{2}$. These relationships are depicted visually as a paths in the diagram in Fig. 8A \& B. 


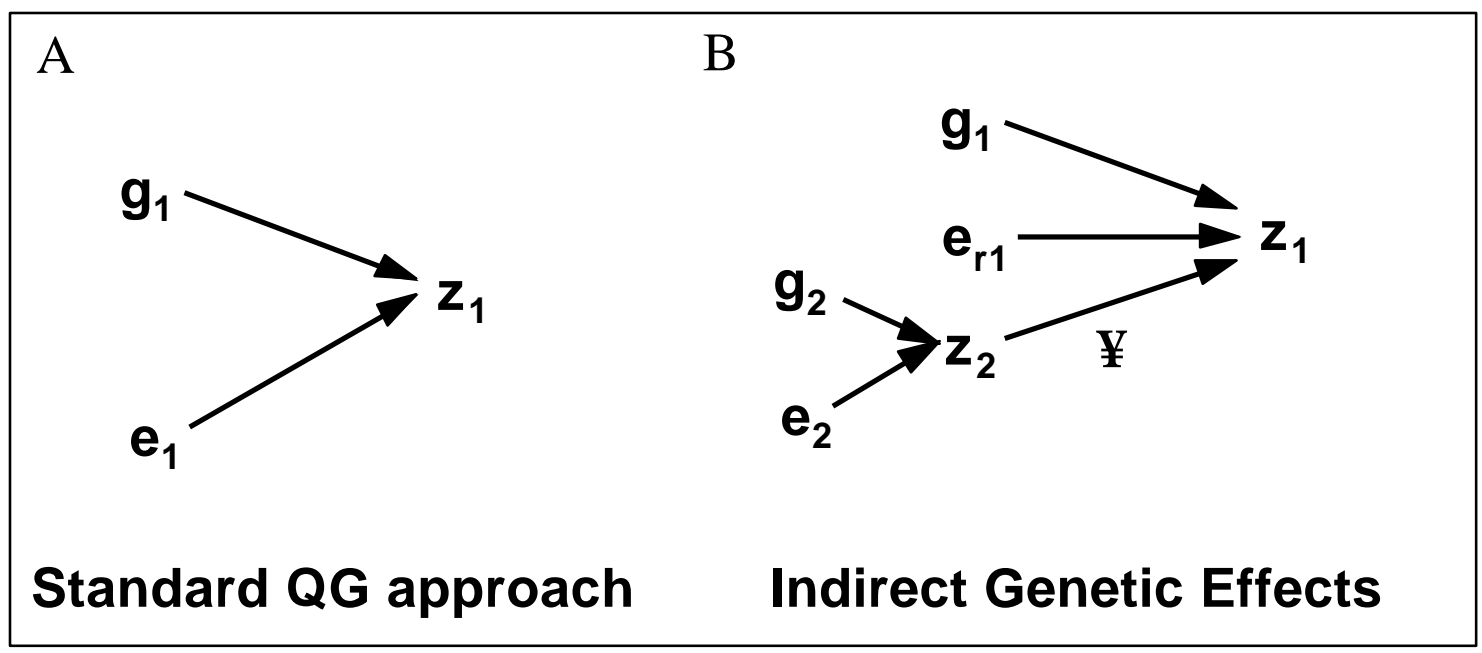

Figure 8. Path diagrams illustrating some of the key sources of phenotypic variation. A) The basic quantitative genetic approach (Falconer \& Mackay 1996), showing that phenotypic variation can be subdivided into genetic effects (additive genetic component; a) and environmental effects (e). B) Indirect genetic effects divide environmental effects into two components, one of which includes the phenotype of a social partner $\left(\mathbf{z}_{2}\right)$. Because those phenotypes are themselves influenced by genetic variation $\left(\mathbf{a}_{2}\right)$, an indirect route of influence is defined from genes in one individual to the phenotype of another, via a path with coefficient $¥$. Because selection may be acting on the phenotype of the social partner, evolution in the focal individual's traits can occur via such indirect effects. After Moore et al. (1997).

An interesting example of indirect genetic effects between the sexes exists in Drosophila melanogaster. Male seminal fluid contains substances that both decrease female propensity to re-mate and increase egg-laying (Rice 1996). In addition, male mating speed depends on the genetic line of the female involved (Casares et al. 1993). In inbred strains of mice, agonistic behavior depended on the strain of the opponent; aggression was increased and dominance relationships were more clear-cut when the opponent was of a different strain (Hughes 1989). Female responses to courtship displays can alter the nature and intensity of those displays (e.g., guppies, Poecilia reticulata, Houde 1997). Similarly, a recent history of female response to male courtship can lead to a change in male behavior in the future via associative learning (e.g., Domjan et al. 1998). All these examples indicate that important phenotypes involved in mating interactions are influenced by the phenotypes of social partners.

Initial models of indirect genetic effects via social partners (Moore et al. 1997) indicate that (1) the indirect genetic component of focal trait variation can have major effects on the rates of evolutionary change, and (2) evolution can proceed via indirect effects even if genetic variation in the focal trait is lacking. These results suggest that indirect genetic effects in mating interactions could have significant effects on divergence in mating patterns between populations. Yet, specific hypotheses about how indirect genetic effects shape evolutionary trajectories induced by conflict is currently lacking. Nevertheless, this approach suggests some general empirical avenues that might be useful.

\subsection{Aiding empiricism: From framework to useful data}


The value of any conceptual framework lies in its ability to organize and stimulate empirical study. Selection theory and quantitative genetics approaches have their empirical advantages and disadvantages, and no doubt those will be factors in specific applications of this framework. However, selection theory and quantitative genetics have a major conceptual benefit in specifying explicit relationships between variables. Many of these relationships will be hard to measure quantitatively, but I suggest that a conceptual framework based on these ideas stimulates new qualitative hypotheses and empirical approaches.

For example, an extremely important consequence of meeting the challenge of explaining diversity in mating patterns via this framework is that studies of single populations will not be very illuminating. Such studies will continue to document diversity and be helpful in exploring the range of relationships that can exist. In addition, we can understand more fully the current selective forces acting on particular combinations of traits. But, studies of single population cannot provide much insight into the processes involved in initial divergence. Therefore, testing what factors are most important (e.g., selective versus genetic) in producing divergence requires parallel studies in closely related species or two populations of the same species. These studies must be tightly coordinated such that similar methods can reveal key differences, which can then be scrutinized in order to understand the factors that contributed to their production.

One systematic way of exploring initial differences might be to collect data on mating patterns in two populations and compare measures of variances and covariances within and between the components of within-pair (number of mates, fecundity per mate, paternity) plus extra-pair success (number of mates, fecundity per mate, paternity; Webster et al. 1995) for males and analogous variables for females (Fig. 9). The covariance terms in particular can be used to identify possible conflicting demands affecting mating success. However, the most interesting potential use of this approach would be to measure the correlations between these fitness measures and trait values, reciprocally between the sexes (Fig. 9). This would help identify potential conflict (or cooperation) gradients and the traits that produce them. A parallel analysis of this sort might reveal surprising differences between populations that could be the focus of future work.

Such methods have their drawbacks, but here I emphasize that application of this approach provides a systematic initial survey of the differences in evolutionary forces between populations. This might reduce the likelihood of apparent differences between populations being generated by differences in investigator emphasis. For example, in red-winged blackbirds, some key differences exist between eastern and western populations in how extra-pair copulations occur (Westneat 1992, Gray 1996). Neither the cause of these differences nor their full selective consequences are known. An initial analysis that could be useful might be to measure fitness components as laid out in Fig. 9, search for major differences between populations in variances and covariances, and then measure the correlations between those and a set of male and female traits. This might identify some key differences that could form the focus of parallel experimental manipulations. For example, similar manipulations of food resources in two populations might reveal different effects on male mate-guarding behavior (e.g., Westneat 1994). 


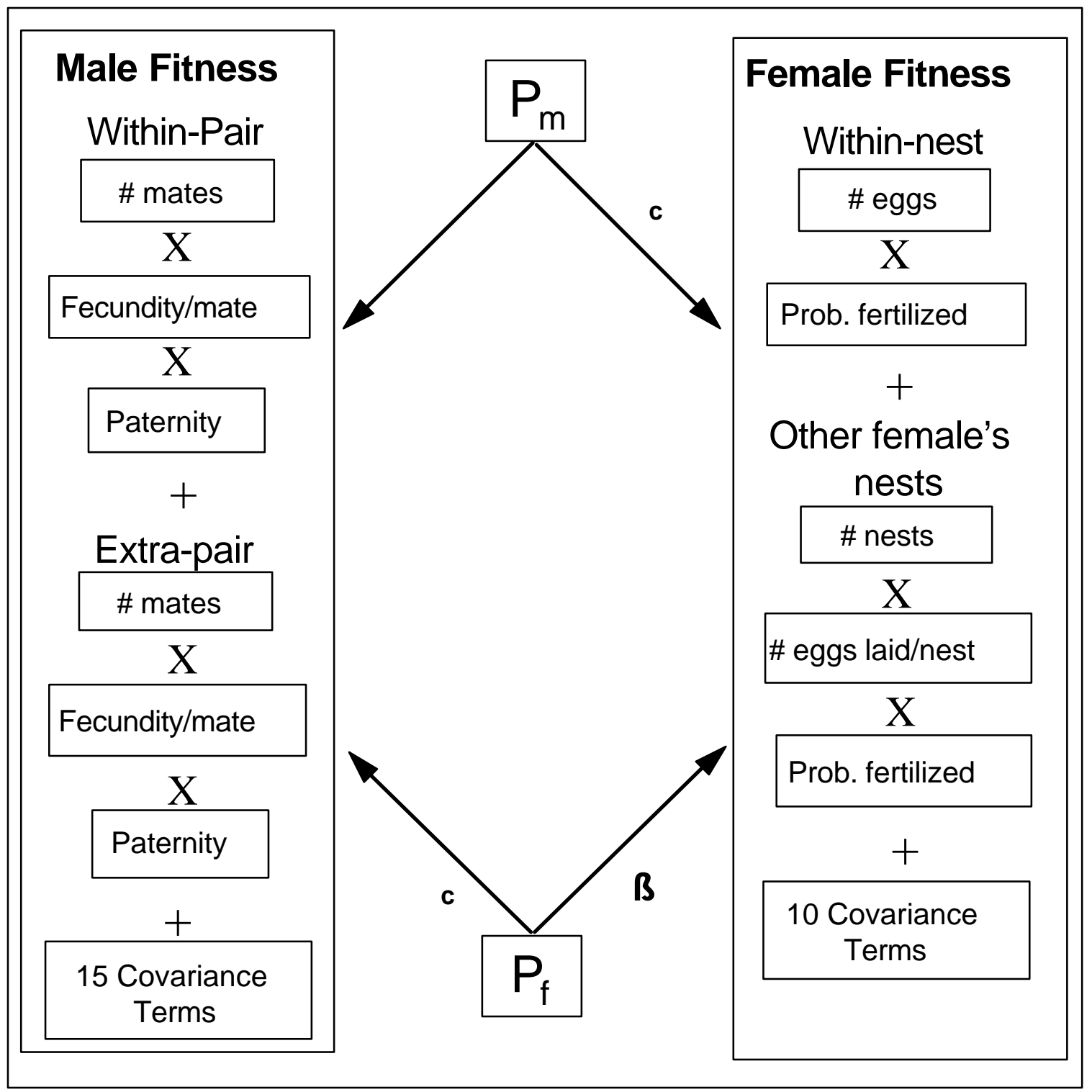

Figure 9. Diagram of a multivariate approach to measuring selection and conflict gradients. Fitness is divided out into 6 component parts for males (Webster et al. 1995); each of these six is combined in dyads to produce 15 covariance terms. Similarly, female fitness is divided into 5 parts plus 10 covariances (note: indirect effects on offspring fitness, such as mate's genetic quality and or paternal care are not included here, but could be in a larger analysis). Covariances would reflect some common underlying cause; a negative covariance might reflect a trade-off (e.g. more within-pair mates might reduce paternity per mate), whereas a positive covariance might reflect the joint effect of some other variable (high numbers of social mates linked with high paternity might indicate female preferences for a male trait). A first pass survey of the effects of male and female phenotypic traits on fitness components and, especially, on covariances between components in both sexes could provide some initial guidance to which traits and reproductive activities produce conflict (or cooperation) and so might induce selection on response traits.

Phenotypic engineering using hormones (e.g., Ketterson \& Nolan 1992) might alter male phenotypes in parallel ways in the two populations. Manipulations of traits suspected of influencing social interactions between males and females could provide insight into two aspects of social selection leading to 
divergence; experimental confirmation of the magnitude of the conflict gradient generated by the trait, as well as information about how particular traits in partners might respond to conflict (Figure 10). An interaction effect, between the extent of the manipulated trait and the value of a target response trait in the partner on the partner's fitness would reveal evolutionarily relevant forces acting on responses to conflict. Presumably, in cases that are diverging, such an experiment and analysis done in parallel in two populations would reveal differences in the quality of response traits, suggesting adaptive differences. Alternatively, if no such differences in effects were found, any differences between populations might be due instead to differences in genetics (e.g., level of variation, covariances, or extent of indirect genetic effects).

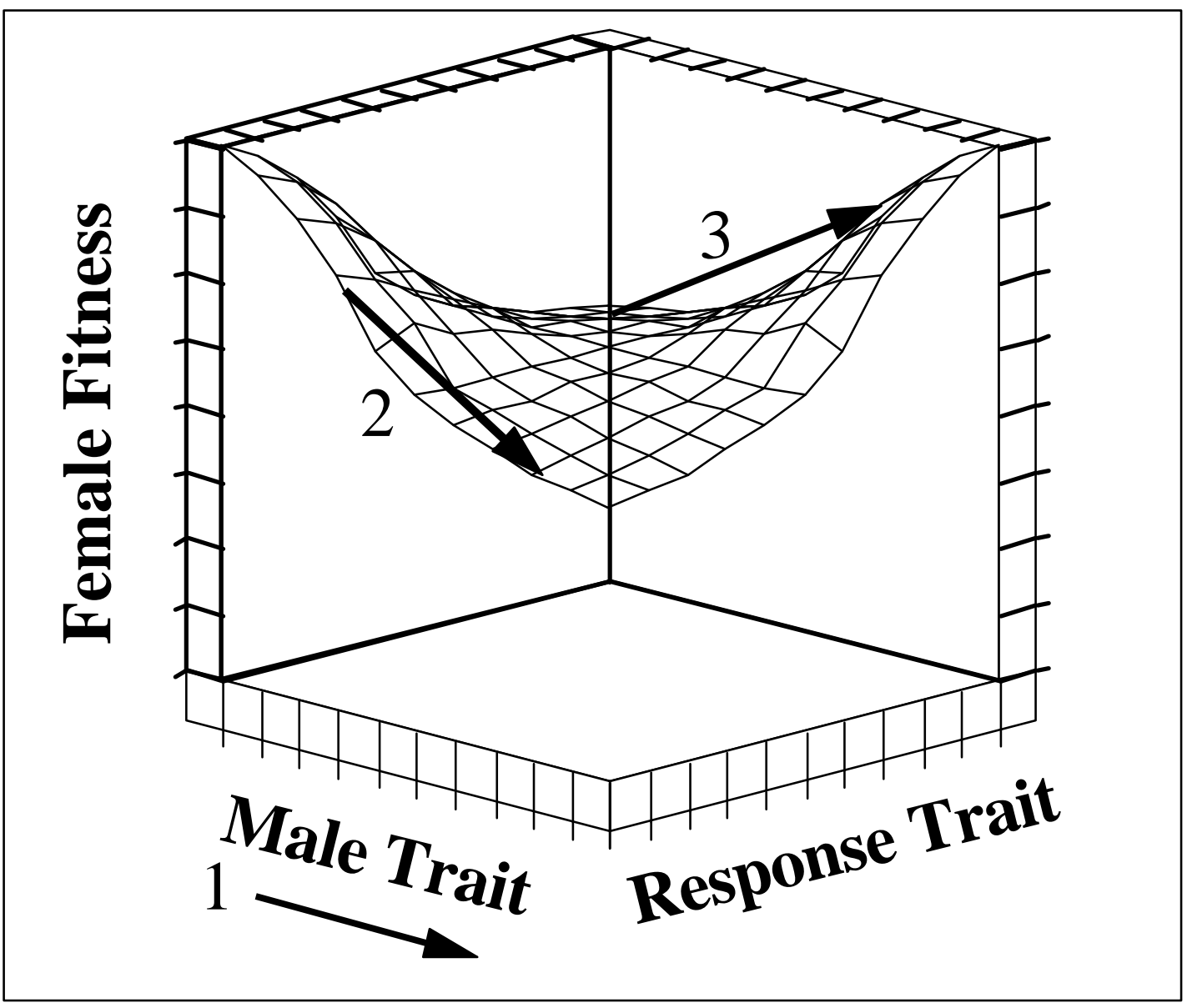

Figure 10. Three dimensional plot showing a male trait, a female response trait, and their combined effect on fitness. Arrow 1 indicates an experimental manipulation of the male trait; 2 and 3 show the predicted effects on female fitness depending on the female trait value. Experiments like this conducted with an array of potential response traits in mind would allow a more complete understanding of the ways in which conflict might produce diverse evolutionary trajectories.

Testing how quantitative genetic parameters are influencing divergence between populations is likely to prove the most difficult aspect of exploring this conceptual view of divergence. Many previous workers have argued for the importance of quantitative genetic approaches to studying evolution (e.g., 
Boake 1994). It seems likely that studies of interacting phenotypes and indirect genetic effects will be even more difficult, especially in field situations. Interacting phenotypes are generally composed of traits whose values are changing quickly and are difficult to measure. In addition, constructing a breeding design with a sample size that would allow for measures of genetic variances adds many difficulties (Arnold 1994). For many systems, it is possible that the key parameters will simply not be measurable.

I will not go into all these problems in detail, but will note in passing that such potential difficulties should not dissuade us in exploring the nature of fitness and trait variation in mating interactions. Neither identifying factors of importance within single populations, nor taking crude measures of complex variables and measuring correlations in broad comparative studies, will lead to adequate explanations of diversity in mating patterns. These problems of empirical studies exist regardless of the conceptual approach. Here I point out that the approach I have described does suggest some different directions for research. Solutions to potential empirical difficulties may emerge once it has been more fully used.

\section{Summary and conclusions}

Genetics and the study of mating patterns are now inextricably linked. Much of the interesting theory in many taxa now focuses on factors affecting fertilization success. Yet, we cannot see fertilization, and so genetic tools allow us to measure fertilization success much better than we could before.

An array of intriguing hypotheses has been generated by the results of recent genetic studies, and very few of them have been well tested. By far one of the most important results of genetic studies has been a more balanced view of how each sex influences mating outcomes. Studies of female behavior will continue to benefit from genetic tools. A brief flurry of paternity and paternal care studies has waned, but many intriguing questions remain, and in the right system with careful experiments, specific predictions of theory can be tested using genetic tools as an aid. Studies of sexual selection are blossoming, and genetic tools are a critical research tool. Finally, ecological studies have used genetic tools to look for important correlations; second generation experimental studies need to follow, and genetic tools will be important in such studies as well.

Genetic tools have their limitations, however. It is clear that while they are critical in testing many hypotheses, other information is equally vital. Detailed behavioral work is required for understanding female behavior, for identifying the types of responses males might have to reduced paternity, and to understanding the ways in which male advertisements lead to enhanced fertilization success. Both behavioral and ecological data will be needed in combination with genetic data to fully understand how ecology influences mating dynamics.

The above should occupy researchers for some time. However, I predict studies of the above will not solve the challenging issue of why species differ so much in their mating patterns and behavior. I've offered the skeletal outlines of a somewhat novel framework that considers hypotheses about the evolution of mating diversity. This framework includes ideas from quantitative genetics. It is my opinion that if meeting the challenge of explaining diversity is to be a research goal in the future, that ideas from quantitative genetics will provide a new influence on mating systems research. I also contend that a framework based on selection theory and quantitative genetics allows for an unbiased evaluation of the influences of each sex on the evolution of mating patterns. 
Molecular tools will not disappear, but rather we will approach mating systems with an array of tools. Behavioral, ecological, experimental, conceptual, and both molecular and quantitative genetic approaches combined in an organized comparative approach may yet allow us to understand a fascinating and important evolutionary puzzle. The evolution of diversity in mating patterns is a "species of knowledge" that has the appearance of confirming Kant's prediction of being fascinating yet unexplainable. I refuse to be so pessimistic. The progress in understanding mating patterns that has occurred over the past 20 years shows no sign of diminishing. Whether or not we do eventually understand the full diversity of mating patterns is not clear. But, I think it will be fun to try, and even the limited advances we make will help us further comprehend the ways evolutionary processes shape males and females.

\section{Acknowledgements}

The ideas presented in this paper have been influenced by many of my colleagues. Selection theory approaches to sexual conflict arose from many wonderful discussions with Andy Sih, Butch Brodie, Allen Moore, Phil Crowley, and Craig Sargent. My own empirical research on mating patterns has been supported by The National Science Foundation and the University of Kentucky. Finally, I thank Marco Apollonio and Marco Festa-Bianchet for organizing the workshop of which this paper was a part, the other participants at the workshop for their ideas, and Marco Appolonio, Marco FestaBianchet, Meg Hatch, Wendy Hein, Herman Mays, Joe Poston, and Pat Weatherhead for many useful comments on earlier drafts of the manuscript.

\section{References}

Alatalo, R. V., A. Carlson, A. Lundberg and S. Ulfstrand, The conflict between male polygamy and female monogamy: the case of the pied flycatcher Ficedula hypoleuca. Am. Nat. 117 (1981) 738753.

Alatalo, R. V., L. Gustafsson and A. Lundberg, High frequency of cuckoldry in pied and collared flycatchers. Oikos 42 (1984) 41-47.

Andrew, R. J., The displays given by passerines in courtship: a review. Ibis 103a (1961a) 315-348.

Andrew, R. J., The displays given by passerines in reproductive fighting: a review. Ibis 103a (1961b) 549-579.

Aristotle, The History of Animals (Balme DM, translator) (Harvard University Press, Cambridge, MA, $350 \mathrm{BCE})$.

Arnold, S. J., Multivariate inheritance and evolution: A review of concepts, in: Quantitative Genetic Studies of Behavioral Evolution, ed. C. R. B. Boake (University of Chicago Press, Chicago, 1994), pp. 17-48.

Arnold, S. J.,and D. Duvall, Animal mating systems: a synthesis based on selection theory. Am. Nat . 143 (1994) 317-348.

Arnold, S. J. and M. Wade, On the measurement of natural and sexual selection: Theory. Evolution 38 (1984) 709-719. 
Barash, D. P., Sociobiology of rape in mallards (Anas platyrhynchos): responses of the male. Science 197 (1977) 788-789.

Beecher, M. D. and I. M. Beecher, Sociobiology of bank swallows: reproductive strategy of the male. Science 205 (1979) 109-116.

Birkhead, T. R., Behavioural adaptations to high density nesting in the common guillemot Uria aalge. Anim. Behav. 26 (1978) 321-331

Birkhead, T. R., L. Atkin and A. P. Møller, Copulation behaviour of birds. Behaviour 101 (1987) 101-138.

Birkhead, T. R. and J. D. Biggins, Reproductive synchrony and extra-pair copulations in birds. Ethology 74 (1987) 320-334.

Birkhead, T. R. and A. P. Møller, Sperm competition in birds: evolutionary causes and consequences (Academic Press, London, 1992).

Birkhead, T. R. and A. P. Møller, Sperm competition and sexual selection. (Academic Press, San Diego, 1998).

Boake, C. R. B., ed, Quantitative genetic studies of behavioral evolution (University of Chicago Press, Chicago, 1994).

Brooker, M. G., I. Rowley, M. Adams and P. R. Baverstock, Promiscuity: an inbreeding avoidance mechanism in a socially monogamous species? Behav. Ecol. Sociobiol. 26 (1990) 191-199.

Brown, C. R. and M. B. Brown, Genetic evidence for multiple parentage in broods of cliff swallows. Behav. Ecol. Sociobiol. 23 (1988) 379-387.

Brown, W. D., B. J. Crespi, and J. C. Choe, Sexual conflict and the evolution of mating systems, in The Evolution of Mating Systems in Insects and Arachnids, ed. J. C. Choe and B. J. Crespi (Cambridge University Press, Cambridge, 1997), pp. 352-377.

Burke, T., DNA fingerprinting in birds. Nature 327 (1987) 149-152.

Burns, J. T., K. M. Cheng and F. McKinney, Forced copulation in captive mallards. I. Fertilization of eggs. Auk 97 (1980) 875-879.

Carey, M. and V. Nolan, Jr., Population dynamics of indigo buntings and the evolution of avian polygyny. Evolution 33 (1979) 1180-1192.

Casares, P., M. C. Carracedo, E. San Miguel, R. Pineiro and L. Garcia-Florez, Male mating speed in Drosophila melanogaster: Differences in genetic architecture and in relative performance according to female genotype. Behav. Genet. 23 (1993) 349-358.

Cheverud, J. M. and A. J. Moore, Quantitative genetics and the role of the environment provided by relatives in the evolution of behavior, in Quantitative Genetic Studies of Behavioral Evolution, ed C. R. B. Boake (University of Chicago Press, Chicago, 1994), pp. 67-100.

Crook, J. H., The evolution of social organisation and visual communication in the weaver birds (Ploceinae). Behaviour Suppl. 10 (1964) 1-178

Crook, J. H., Sexual selection, dimorphism, and social organization in the primates, in Sexual selection and the descent of man, 1871-1971, ed. B. Campbell (Aldine, Chicago, 1972), pp. 231-281

Crow, J. F., Some possibilities for measuring selection intensities in man. Human Biology 30 (1958) 113

Dale, S. and T. Slagsvold, Polygyny and deception in the pied flycatcher: Can females determine male mating status? Anim. Behav. 48 (1994) 1207-1217.

Darwin, C., The Descent of Man and Selection in Relation to Sex (John Murray, London, 1871). 
Davies, N. B., Mating systems, in Behavioural Ecology: An Evolutionary Approach, 3rd ed., eds. J. R. Krebs and N. B. Davies (Blackwell Science Publications, Oxford, 1991), pp. 263-294.

Davies, N. B., Dunnock Behaviour and Social Evolution Oxford University Press, Oxford, 1992).

Dawkins, R. D., The Selfish Gene (Oxford University Press, Oxford, UK, 1976).

Dawkins, R. D., The Extended Phenotype (W. H. Freeman, San Francisco, 1982).

Dixon, A., D. Ross, S. L. C. O'Malley and T. Burke, Paternal investment inversely related to degree of extra-pair paternity in the reed bunting. Nature 371 (1994) 698-700.

Domjan, M., E. Blesbois and J. Williams, The adaptive significance of sexual conditioning: Pavlovian control of sperm release. Psych. Sci. 9 (1998) 411-415

Dunn, P. O., L. A. Whittingham, J. T. Lifjeld, R. J. Robertson and P. T. Boag, Effects of breeding density, synchrony, and experience on extra-pair paternity in tree swallows. Behav. Ecol. 5 (1994) 123-129.

Emlen, S. T. and L. W. Oring, Ecology, sexual selection, and the evolution of mating systems. Science 197 (1977) 215-223.

Foltz, D. W., Genetic evidence for long-term monogamy in a small rodent, Peromyscus polionotus. Am. Nat. 117 (1981) 665-675.

Frederick, P. C., Responses of male white ibises to their mate's extra-pair copulations. Behav. Ecol. Sociobiol. 21 (1987) 223-228.

Gavin, T. A. and E. K. Bollinger, Multiple paternity in a territorial passerine: the bobolink. Auk 102 (1985) 550-555.

Gelter, H. P. and H. Tegelström, High frequency of extra-pair paternity in Swedish pied flycatchers revealed by allozyme electrophoresis and DNA fingerprinting. Behav. Ecol. Sociobiol. 31 (1992) $1-8$

Gibbs, H. L., P. J. Weatherhead, P. T. Boag, B. N. White, L. M. Tabak and D. J. Hoysak, Realized reproductive success of polygynous red-winged blackbirds revealed by DNA markers. Science 250 (1990) 1394-1397

Gomendio, M., A. H. Harcourt and E. R. S. Roldan, Sperm competition in mammals, in Sperm Competition and Sexual Selection, ed T. R. Birkhead and A. P. Møller (Academic Press, San Diego, 1998), pp.667-756.

Gowaty, P. A. and A. A. Karlin, Multiple maternity and paternity in single broods of apparently monogamous eastern bluebirds (Sialia sialis). Behav. Ecol. Sociobiol. 15 (1984) 91-95.

Grafen, A., Opportunity cost, benefit and degree of relatedness. Anim. Behav. 28 (1980) 967-968.

Gray, E. M., Female control of paternity in a western population of red-winged blackbirds (Agelaius phoeniceus). Behav. Ecol. Sociobiol. 38 (1996) 267-278.

Hamilton, W. D., The genetical evolution of social behaviour. J. Theor. Biol. 7 (1964) 1-52.

Hanken, J. and P. W. Sherman, Multiple paternity in Belding's ground squirrels. Science 212 (1981) 351-353

Hasselquist, D., S. Bensch and T. von Schantz, Low frequency of extra-pair paternity in the polygynous great reed warbler Acrocephalus arundinaceus. Behav. Ecol. 6 (1995) 27-38

Hasselquist, D., S. Bensch and T. von Schantz, Correlation between male song repertoire, extra-pair fertilizations and offspring survival in the great reed warbler. Nature 381 (1996) 229-232. 
Hedrick, A. V., The heritability of mate-attractive traits: A case study on field crickets, in Quantitative Genetic Studies of Behavioral Evolution, ed. C. R. B. Boake (University of Chicago Press, Chicago, 1984), pp. 228-250.

Heisler, I. L., Quantitative genetic models of the evolution of mating behavior, in Quantitative Genetic Studies of Behavioral Evolution, ed. C. R. B. Boake (University of Chicago Press, Chicago, 1984), pp. 101-125.

Hogg, J. T. and S. H. Forbes, Mating in bighorn sheep: Frequent male reproduction via a high-risk "unconventional" tactic. Behav. Ecol. Sociobiol. 41 (1997) 33-48.

Hoi, H. and M. Hoi-Leitner, An alternative route to coloniality in the bearded tit: females pursue extrapair fertilizations. Behav. Ecol. 8 (1997) 113-119

Hoogland, J. L. and P. W. Sherman, Advantages and disadvantages of bank swallow (Riparia riparia) coloniality. Ecol. Monogr. 46 (1976) 33-58

Houde, A. E., Sex, Color, and Mate Choice in Guppies (Princeton University Press, Princeton, 1997).

Houston, A. I., Parental effort and paternity. Anim. Behav. 50 (1995) 1635-1644.

Hughes, A. L., Interaction between strains in the social relations of inbred mice. Behav. Genet. 19 (1989) 685-700.

Hunt, S., A. T. D. Bennett, I. C. Cuthill, and R. Griffiths, Blue tits are ultraviolet tits. Proc. Roy. Soc. Lond. B, Biol. Sci. 265 (1998) 451-455.

Jeffreys, A. J., V. Wilson and S. L. Thein, Hypervariable "minisatellite" regions in human DNA. Nature 314 (1985) 67-73.

Johnsen, A., S. Andersson, J. Örnborg and J. T. Lifjeld, Ultraviolet plumage ornamentation affects social mate choice and sperm competition in bluethroats (Aves: Luscinia s. svecica): a field experiment. Proc. Roy. Soc. Lond. B, Biol. Sci. 265 (1998) 1313-1318.

Joste, N., J. D. Ligon, and P. B. Stacey, Shared paternity in the acorn woodpecker. Behav. Ecol. Sociobiol. 17 (1985) 39-41.

Kant, I., Critique of Pure Reason, translator N. K. Smith, 1956 (St. Martin's Press, London, 1781).

Kempenaers, B., G. R. Verheyen, M. Van den Broeck, T. Burke, C. Van Broeckhoven and A. A. Dhondt, Extra-pair paternity results from female preference for high-quality males in the blue tit. Nature 357 (1992) 494-496.

Kempenaers, B. and B. C. Sheldon, The study of paternity and paternal care: pitfalls and problems. Anim. Behav. 53 (1997) 423-427.

Ketterson, E. D. and V. Nolan, Jr., Hormones and life histories: An integrative approach. Am. Nat. 140 (1992) 533-562.

Leffelaar, D. and R. J. Roberston, Do male tree swallows guard their mates? Behav. Ecol. Sociobiol. 16 (1984) 73-79.

Lifjeld, J. T., P. O. Dunn, R. J. Robertson and P. T. Boag, Extra-pair paternity in monogamous tree swallows. Anim. Behav. 45 (1993) 213-229.

Lifjeld, J. T. and R. J. Robertson, Female control of extra-pair fertilization in tree swallows. Behav. Ecol. Sociobiol. 31 (1992) 89-96.

Lifjeld, J. T., T. Slagsvold, S. Dale and H. Ellegren, A sexually selected paradox in the pied flycatcher: Attractive males are cuckolded. Auk 114 (1997) 112-115. 
Lifjeld, J. T., T. Slagsvold and H. M. Lampe, Low frequency of extra-pair paternity in pied flycatchers revealed by DNA fingerprinting. Behav. Ecol. Sociobiol. 29 (1991) 95-101.

Maynard Smith, J., Parental investment: A prospective analysis. Anim. Behav. 25 (1977) 1-9

Maynard Smith, J., The Evolution of Sex (Cambridge University Press, Cambridge, U.K., 1978).

McCracken, G. F. and J. Bradbury, Paternity and genetic heterogeneity in the polygynous bat, Phyllostomus hastatus. Science 198 (1977) 303-306.

McKinney, F., S. R. Derrickson and P. Mineau, Forced copulation in waterfowl. Behaviour 86 (1983) 250-294.

Møller, A. P., House sparrow Passer domesticus communal displays. Anim. Behav. 35 (1987) 203210.

Møller, A. P., Sexual Selection and the Barn Swallow (Oxford University Press, Oxford, U. K., 1994).

Møller, A. P., Sperm competition and sexual selection, in Sperm Competition and Sexual Selection, eds. T. R. Birkhead and A. P. Møller (Academic Press, San Diego, 1998), pp.55-90.

Møller, A. P. and T. R. Birkhead, A pairwise comparative method as illustrated by copulation frequency in birds. Am. Nat. 139 (1992) 644-656.

Møller, A. P. and T. R. Birkhead, Cuckoldry and sociality: a comparative study of birds. Am. Nat. 142 (1993a) 118-140.

Møller, A. P. and T. R. Birkhead, Certainty of paternity covaries with paternal care in birds. Behav. Ecol. Sociobiol. 33 (1993b) 361-368.

Møller, A. P., N. Saino, G. Taramino, P. Galeotti and S. Ferrario, Paternity and multiple signaling: effects of a secondary sexual character and song on paternity in the barn swallow. Am. Nat. 151 (1998) 236-242.

Moore, A. J. and C. R. B. Boake, Optimality and evolutionary genetics: Complementary procedures for evolutionary analyses in behavioural ecvology. Trends Ecol. Evol. 9 (1994) 69-72.

Moore, A. J., E. D. Brodie, III and J. B. Wolf, Interacting phenotypes and the evolutionary process: I. Direct and indirect genetic effects of social interactions. Evolution 51 (1997) 1352-1362.

Mulder, R. A., P. O. Dunn, A. Cockburn, K. A. Lazenby-Cohen and M. J. Howell, Helpers liberate female fairy-wrens from constraints on extra-pair mate choice. Proc Roy Soc Lond B Biol. Sci. 255 (1994) 223-229.

Mumme, R. L., W. D. Koenig, R. M. Zink and J. A. Marten, Genetic variation and parentage in a California population of acorn woodpeckers. Auk 102 (1985) 305-312.

Neel, J. V. and W. J. Schull, Human Heredity (University of Chicago Press, Chicago, 1954).

Neudorf, D. L., B. J. M. Stutchbury and W. H. Piper, Covert extra-territorial behavior of female hooded warblers. Behav. Ecol. 8 (1997) 595-600.

Ollson, M. and T. Madsen, Sexual selection and sperm competition in reptiles, in Sperm Competition and Sexual Selection, eds. T. R. Birkhead and A. P. Møller (Academic Press, San Diego, 1998), pp.503-578.

Orians, G. A., On the evolution of mating systems in birds and mammals. Am. Nat. 103 (1969) 589603.

Otter, K., L. Ratcliffe and P. T. Boag, Extra-pair paternity in the black-capped chickadee. Condor 96 (1994) 218-222. 
Parker, G. A., Sperm competition and its evolutionary effect on copula duration in the fly Scatophaga stercoraria. J. Insect Physiol. 15 (1970) 1301-1328.

Parker, G. A., Sexual selection and sexual conflict. In: Sexual selection and Reproductive Competition in Insects, eds. M. S. Blum and N. A. Blum (Academic Press, New York, 1979), pp. 123-166.

Parker, G. A., Sperm competition and the evolution of animal mating strategies, in Sperm Competition and the Evolution of Animal Mating Systems, ed. R. L. Smith (Academic Press, Orlando, 1984), pp 1-60.

Parker, G. A., R. R. Baker and V. G. F. Smith, The origin and evolution of gamate dimorphism and the male-female phenomenon. J. Theor. Biol. 36 (1972) 529-533.

Pemberton, J. M., S. D. Albon, F. E. Guiness, T. H. Clutton-Brock and G. A. Dover, Behavioural estimates of male mating success tested by DNA fingerprinting in a polygynous mammal. Behav. Ecol. 3 (1992) 66-75.

Rätti, O., M. Hovi, A. Lundberg, H. Tegelström and R. V. Alatalo, Extra-pair paternity and male characteristics in the pied flycatcher. Behav. Ecol. Sociobiol. 37 (1995) 419-425.

Rausher, M. D., The measurement of selection on quantitative traits: Biases due to environmental covariances between traits and fitness. Evolution 46 (1992) 616-626.

Reyer, H.-U., K. Bollmann, A. R. Schläpfer, A. Schymainda and G. Klecack, Ecological determinants of extrapair fertilizations and egg dumping in alpine water pipets (Anthus spinoletta). Behav. Ecol. 8 (1997) 534-543.

Reynolds, J. D., Animal breeding systems. Trends Ecol. Evol. 11 (1996) 68-72.

Rice, W. R., Sexually antagonistic male adaptation triggered by experimental arrest of female evolution. Nature 381 (1996) 232-234.

Ridley, M., Paternal care. Anim. Behav. 26 (1978) 904-932.

Saetre, G. P., S. Dale and T. Slagsvold, Female peid flycatchers prefer brightly coloured males. Anim. Behav. 48 (1994) 1407-1416.

Saino, N., C. Primmer, H. Ellegren, A. P. Møller, An experimental study of paternity and tail ornamentation in the barn swallow (Hirundo rustica). Evolution 51 (1997) 562-570.

Schwagmeyer, P. L., R. C. St. Clair, J. D. Moodie, T. C. Lamey, G. D. Schnell and M. N. Moodie, Species differences in male parental care in birds: A reexamination of correlates with paternity. Auk 116 (1999) 487-503.

Searcy, W. A., D. Eriksson and A. Lundberg, Deceptive behavior in pied flycatchers. Behav Ecol Sociobiol. 29 (1991) 167-175.

Searcy, W. A. and K. Yasukawa, Polygyny and Sexual Selection in Red-winged Blackbirds (Princeton University Press, Princeton, NJ, 1995).

Sheldon, B. C., Sperm competition in the chaffinch: the role of the female. Anim. Behav. 47 (1994) 163-173.

Sherman, P. W., Electrophoresis and avian genealogical analyses. Auk 98 (1981) 419-422.

Sherman, P. W. and M. L. Morton, Extra-pair fertilizations in mountain white-crowned sparrows. Behav. Ecol. Sociobiol. 22 (1988) 413-420.

Silver, R., H. Andrews and G. F. Ball, Parental care in an ecological perspective: A quantitative analysis of avian subfamilies. Amer. Zool. 25 (1985) 823-840. 
Smith, H. G., R. Montgomerie, T. Poldmaa, B. N. White and P. T. Boag, DNA fingerprinting reveals relation between tail ornaments and cuckoldry in barn swallows, Hirundo rustica. Behav. Ecol. 2 (1991) 90-98.

Smith, S. M. , Extra-pair copulations in black-capped chickadees: the role of the female. Behaviour 107 (1988) 15-23.

Smith, R. L. (ed.), Sperm Competition and the Evolution of Animal Mating Systems (Academic Press, San Diego, 1984).

Smiseth, P. T. and T. Amundsen, Female bluethroats (Luscinia s. svecica) regularly visit territories of extra-pair males before egg-laying. Auk 112 (1995) 1049-1053.

Stenmark, G., T. Slagsvold and J. T. Lifjeld, Polygyny in the pied flycatcher Ficedula hypoleuca: a test of the deception hypothesis. Anim. Behav. 36 (1988) 1646-1657.

Stresemann, E. in Handbuch der Zoologie. Sauropsida: Aves, eds. W. Kükenthal and T. Krumbach (W. de Gruyter and Co., Berlin, 1927-1934).

Stutchbury, B. J. M., Female mate choice of extra-pair males: breeding synchrony is important. Behav. Ecol. Sociobiol. 43 (1998a) 213-216.

Stutchbury, B. J. M., Extra-pair mating effort of male hooded warblers, Wilsonia citrina. Anim. Behav. 55 (1998b) 553-561.

Stutchbury, B. J. M. and E. S. Morton, The effect of breeding synchrony on extra-pair mating systems in songbirds. Behaviour 132 (1995) 675-690.

Stutchbury, B. J., J. M. Rhymer and E. S. Morton, Extra-pair paternity in hooded warblers. Behav. Ecol. 5 (1994) 384-392.

Stutchbury, B. J. M., W. H. Piper, D. L. Neudorf, S. A. Tarof, J. M. Rhymer, G. Fuller and R. C. Fleischer, Correlates of extra-pair fertilization success in hooded warblers. Behav. Ecol. Sociobiol. 40 (1997) 119-126.

Sundberg, J. and A. Dixon, Old, colourful male yellowhammers, Emberiza citrinella, benefit from extra-pair copulations. Anim. Behav. 52 (1996) 113-122.

Thornhill, R., Sexual selection and nuptial feeding behavior in Bitatacus apicalis (Insecta: Mecoptera). Am. Nat. 110 (1976) 529-548.

Thornhill, R., Rape in Panorpa scorpionflies and a general rape hypothesis. Anim. Behav. 28 (1980) 52-59.

Thornhill, R. and J. Alcock, The Evolution of Insect Mating Systems (Harvard University Press, Cambridge, MA, 1983).

Trivers, R. L., Parental investment and sexual selection, in Sexual selection and the Descent of Man, 1871-1971. ed. B. Campbell (Aldine, Chicago, 1972), pp. 136-179.

Verner, J., The evolution of polygamy in the long-billed marsh wren. Evolution 18 (1964) 252-261.

Wagner, R. H., M. D. Schug and E. S. Morton, Confidence of paternity, actual paternity and parental effort by purple martins. Anim. Behav. 52 (1996) 123-132.

Weatherhead, P. J., Breeding synchrony and extra-pair mating in red-winged blackbirds. Behav. Ecol. Sociobiol. 40 (1997) 151-158.

Weatherhead, P. J., Sequential mating patterns suggest extra-pair mating is not part of a mixed reproductive startegy by female red-winged blackbirds. Proc. Roy. Soc. Lond. B. Biol. Sci. 266 (1999) 1027-1032. 
Weatherhead, P. J. and P. T. Boag, Pair and extra-pair mating success relative to male quality in redwinged blackbirds. Behav. Ecol. Sociobiol. 37 (1995) 81-91.

Weatherhead, P. J. and P. T. Boag, Genetic extimates of annual and lifetime reproductive success in male red-winged blackbirds. Ecology 78 (1997) 884-896.

Weatherhead, P. J., R. Montgomerie, H. L. Gibbs and P. T. Boag, The cost of extra-pair fertilizations to female red-winged blackbirds. Proc. Roy. Soc. Lond. B Biol. Sci. 258 (1994) 315-320.

Weatherhead, P. J. and S. M. Yezerinac, Breeding synchrony and extra-pair mating in birds. Behav. Ecol. Sociobiol. 43 (1998) 217-219.

Webster, M. S., S. Pruett-Jones, D. F. Westneat and S. J. Arnold, Measuring the effects of pairing success, extra-pair copulations and mate quality on the opportunity for sexual selection. Evolution 49 (1995) 1147-1157.

Welty, J. C., The Life of Birds (Saunders College Publishing, Philadelphia, 1972).

Werren, J. H., M. R. Gross and R. Shine, Paternity and the evolution of male parental care. J. Theor. Biol. 82 (1980) 619-631.

West-Eberhard, M. J., Sexual selection, social competition, and evolution. Proc. Amer. Philos. Soc. 123 (1979) 222-234.

West-Eberhard, M. J., Sexual selection, social competition, and speciation. Quart. Rev. Biol. 58 (1983) 155-183.

Westneat, D. F., Extrapair fertilizations in a predominantly monogamous bird: genetic evidence. Anim. Behav. 35 (1987a) 877-886.

Westneat, D. F., Extrapair copulations in a predominantly monogamous bird: observations of behaviour. Anim. Behav. 35 (1987b) 865-876.

Westneat, D. F., Parental care and extrapair copulations in the Indigo Bunting. Auk 105 (1988) 149160.

Westneat, D. F., Genetic parentage in indigo buntings: a study using DNA fingerprinting. Behav. Ecol. Sociobiol. 27 (1990) 67-76.

Westneat, D. F., Do female red-winged blackbirds engage in a mixed mating strategy? Ethology 92 (1992) 7-28.

Westneat, D. F., Polygyny and extra-pair fertilizations in eastern red-winged blackbirds (Agelaius phoeniceus). Behav. Ecol. 4 (1993a) 49-60.

Westneat, D. F., Temporal patterns of within-pair copulations, male mate-guarding, and extra-pair events in the red-winged blackbird (Agelaius phoeniceus). Behaviour 124 (1993b) 267-290.

Westneat, D. F., To guard mates or go forage: Conflicting demands affect the paternity of male redwinged blackbirds. Am. Nat. 144 (1994) 343-354.

Westneat, D. F., Paternity and paternal behavior in red-winged blackbirds. Anim. Behav. 49 (1995) 21-35.

Westneat, D. F. and E. M. Gray, Breeding synchrony and extra-pair fertilizations in two populations of red-winged blackbirds. Behav. Ecol. 9 (1998) 456-464.

Westneat, D. F., P. C. Frederick and R. H. Wiley, The use of genetic markers to estimate the frequency of successful alternative mating tactics. Behav. Ecol. Sociobiol. 21 (1987) 35-45.

Westneat, D. F., P. W. Sherman and M. L. Morton, The ecology and evolution of extrapair copulations in birds, in Current Ornithology, Volume 7, ed. D. Power (Plenum Press, New York, 1990), pp 331-369. 
Westneat, D. F. and P. W. Sherman, Parentage and the evolution of parental behavior. Behav. Ecol. 4 (1993) 66-77.

Westneat, D. F. and P. W. Sherman, Density and extra-pair fertilizations in birds: A comparative analysis. Behav. Ecol. Sociobiol. 41 (1997) 205-216.

Whittingham, L. A., P. O. Dunn and R. J. Robertson, Confidence of paternity and male parental care: an experimental study in tree swallows. Anim. Behav. 46 (1993) 139-147.

Whittingham, L. A. and J. T. Lifjeld, High parental investment in unrelated young: extra-pair paternity and male parental care in house martins. Behav. Ecol. Sociobiol. 37 (1995) 103-108.

Whittingham, L. A., P. D. Taylor and R. J. Robertson, Confidence of paternity and male parental care. Am. Nat. 139 (1992) 1115-1125.

Willson, M. F., The breeding ecology of the yellow-headed blackbird. Ecological Monographs 36 (1966) 51-77.

Winkler, D. W., A general model for parental care. Am. Nat. 130 (1987) 526-543.

Wittenberger, J. F., The evolution of mating systems in birds and mammals, in Handbook of Behavioral Neurobiology, Vol. 3. Social Behavior and Communication, eds. P. Marler and J. Vandenbergh (Plenum Press, New York, 1979), pp. 271-349.

Wolf, J. B., E. B. Brodie, III, J. M. Cheverud, A. J. Moore and M. J. Wade, Evolutionary consequences of indirect genetic effects. Trends Ecol. Evol. 13 (1998) 64-69.

Wolf, J. B., E. B. Brodie, III and A. J. Moore, Interacting phenotypes and the evolutionary process II. Selection resulting from social interactions. Evolution (in press)

Wright, J., Paternity and paternal care. In: Sperm Competition and Sexual Selection, eds. T. R. Birkhead and A. P. Møller (Academic Press, San Diego, 1998), pp. 117-145.

Wright, S., Evolution and Genetics of Populations. 1. Genetic and Biometric Foundations (University of Chicago Press, Chicago, 1968).

Xia, X., Uncertainty of paternity can select against paternal care. Am. Nat. 139 (1992) 1126-1129.

Yezerinac, S. M., P. J. Weatherhead and P. T. Boag, Extra-pair paternity and the opportunity for sexual selection in a socially monogamous bird (Dendroica petechia). Behav. Ecol. Sociobiol. 37 (1995) 179-188.

Yezerinac, S. M. and P. J. Weatherhead, The effects of synchrony and individual quality on extra-pair mating strategies in the socially monogamous yellow warbler. Anim. Behav. 54 (1997) 1393-1403. 